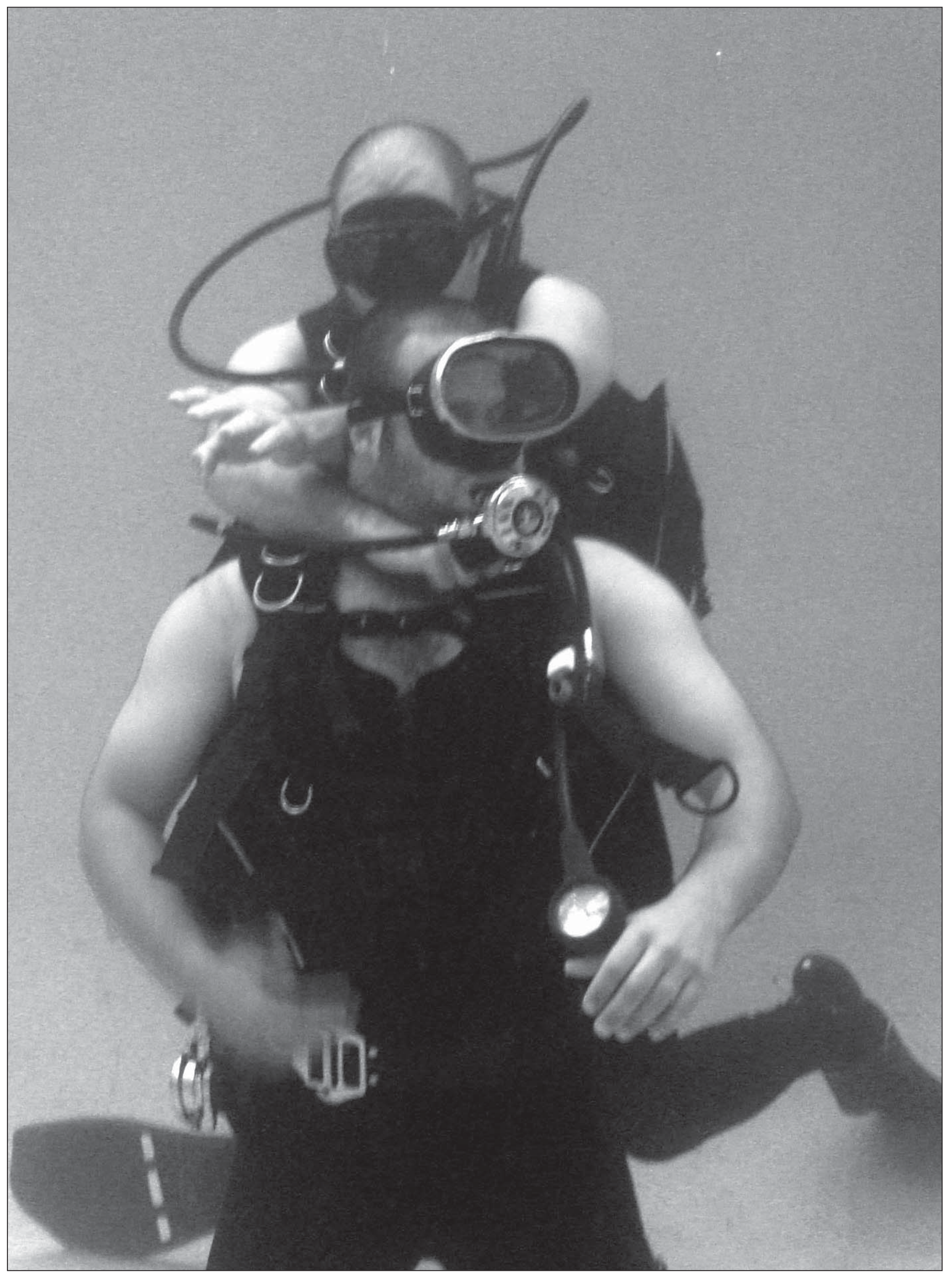




\section{Introducción a las formas \\ de combate cuerpo a cuerpo en el medio acuático}

Miguel Angel Ibáñez Espinosa

\section{Resumen}

En el presente trabajo se describen las formas de combate cuerpo a cuerpo en el medio acuático. Partiendo de un breve recorrido histórico, en el que se analiza la evolución del mismo, se exponen los principales elementos del medio acuático que afectan al combate así como las características de material y de las técnicas a utilizar durante su desarrollo. En el estudio se diferencia el combate acuático en sus dos formas principales, el combate en superficie y el combate en profundidad.

- ¿Sabes quiénes son aquellos que bucean con audacia?

- Si, los buceadores.

- ¿Y es porque han aprendido a bucear o por alguna otra razón?

- Porque han aprendido a bucear.

(Platón - 427-347 a. de C.- en su diálogo Protágoras, XXXIV)

\section{Introducción histórica}

El acercamiento del ser humano al medio acuático se produce en un primer momento debido a un instinto primario de supervivencia y curiosidad. El agua y su entorno satisfacen la necesidad de alimentos del hombre primitivo, y, con el tiempo, le servirá para obtener recursos con los que comerciar. Por ello, en todos los asentamientos humanos cercanos al medio acuático (mares, ríos, lagos, pantanos, marismas, etc.) se aprecian muestras del intento de explotar los recursos que éste les brindaba. Uno de los ejemplos más famosos que puede citarse es el de las buceadoras japonesas ama, quienes bajan a pulmón hasta 23 metros de profundidad para recoger esponjas, coral y perlas del fondo marino. Según parece, esta industria se ha desarrollado desde hace más de 2000 años (Ivars y Rodríguez, 1987).

Página previa:

Forma de estrangulación por la espalda (ushiro-eri-jime)

Todas las fotografías, excepto las señaladas, son cortesía de Miguel Ángel Ibáñez Espinosa. 
La adaptación del hombre a un medio extraño como es el agua será progresiva. En un primer paso se comenzarían desarrollando técnicas que le permitieron mantenerse en su superficie. Posteriormente, esas técnicas evolucionaron hacia el desplazamiento sobre dicha superficie, y por último el hombre llegaría a desplazarse por debajo del agua, es decir, bucear. Paralelamente a estas fases el ser humano usaría los sistemas tradicionales de pesca (a manos desnudas, con arpones, flechas, cañas, redes, nasas, etc.), empleando posteriormente las embarcaciones y por último el buceo.

Según cita Lewillie (en Saavedra, 2003), las más antiguas referencias a la natación aparecen en las pinturas rupestres de la Roca de Gilf Kebir (Egipto), fechadas sobre el 5000 a.C. Cuatro milenios antes de Cristo ya se tienen noticias de tribus salvajes que, entre otras cosas, llevaban peces y perlas como tributo al Emperador Chino Yu. Igualmente, procedentes de estas antiguas culturas han aparecido perlas en ruinas de Babilonia (4500 años a.C.), y diversos jeroglíficos egipcios reflejan esta actividad desde el 2500 a.C. Todos estos hechos demuestran que la natación, y particularmente el buceo, es una actividad que el hombre ha realizado desde tiempos remotos.

Una vez satisfecha esta necesidad, y como suele ser habitual en el ser humano, nacerían otras y entre ellas la de combatir en el medio acuático, ya que el hombre siempre ha procurado contar con la ventaja del entorno en el que se desarrolla la acción. Por ello, es lógico que dicho medio acuático se haya considerado desde antiguo como un elemento a dominar. Ya en el s. IX a.C. los fenicios realizaron acciones de combate subacuatico en el río Tigris ante los asirios, como demuestran ciertos grabados existentes en el Museo Británico que representan al Rey Assur-Nasir-Pal cruzando un río. Estos grabados muestran que los fenicios usaron vejigas de animales para poder respirar bajo el agua.

Figura 1:

Los fenicios realizaron acciones de combate subacuatico en el río Tigris ante los asirios.

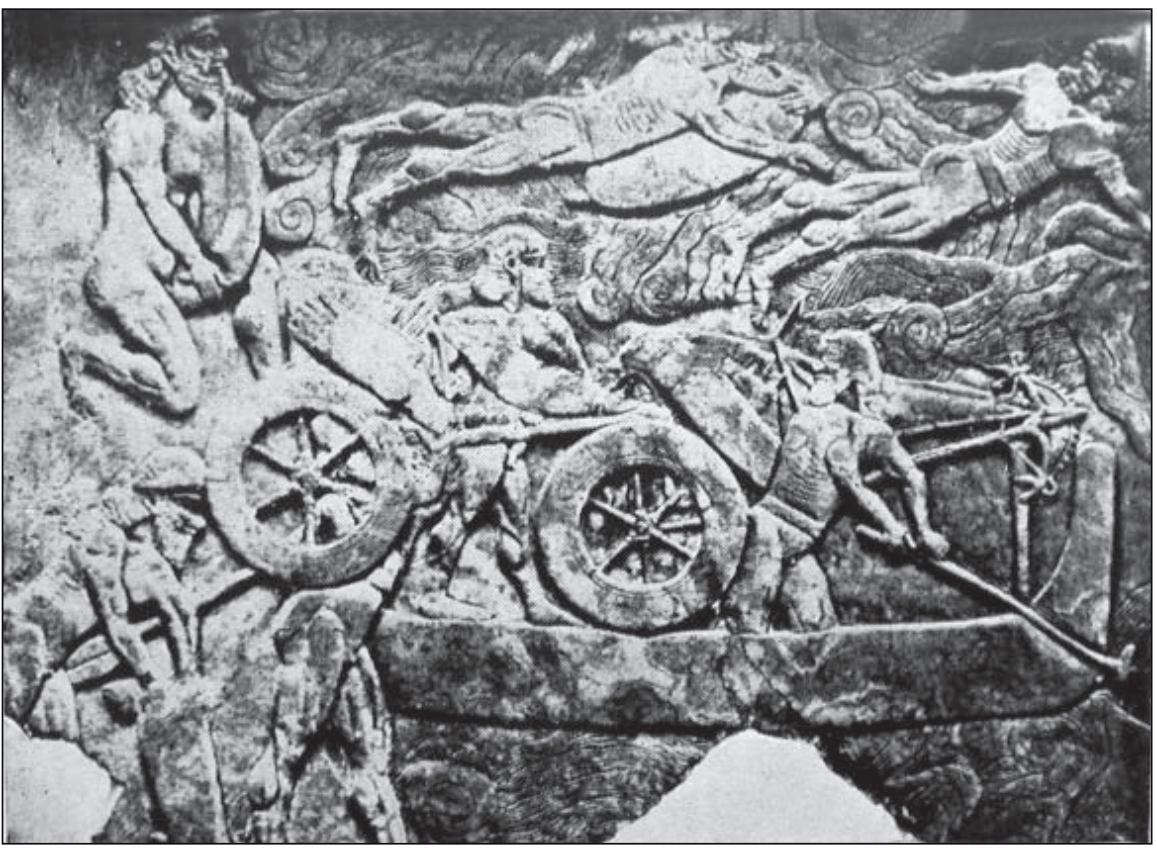

Posteriormente, con la cultura griega clásica se produce un cambio de perspectiva en el uso de la natación, ya que con ellos dejará de ser considerada como un mero elemento para garantizar la supervivencia del hombre y pasa a ser considerada como un aspecto más de la educación y, consecuentemente, del soldado, comenzando a imprimirle un componente militar que se afianzaría con los romanos (Jardi, 1996). Así, en el sitio de Siracusa 
(414 a.C.), Tucídides describe la acción de los nadadores de combate, cuyas intervenciones caracterizan la Guerra del Peloponeso (431-404 a.C.). En el bando contrario, los siracusianos usaron a sus buzos para construir empalizadas de madera bajo el agua. Los romanos, igualmente, tendrían una de las primeras unidades militares de buceadores de combate, los urinatores que ya participaron en el 125 a.C. en la toma de Cartagonova por parte de Escipión. Anteriormente, Tito Livio fue el primero en mencionar a los buzos como rescatadores de tesoros sumergidos.

Uno de los países que más han aportado histórica y documentalmente a las formas del combate acuático es Japón. Siendo un país eminentemente guerrero y marítimo - no en vano se compone de 4 grandes islas y más de 1000 islas menores- debió desarrollar diversas formas de combate en el agua, ya fuese para repeler invasiones externas o para dirimir sus propios conflictos internos. Así, a raíz de los intentos de invasiones del continente asiático por parte de los mongoles (1274-1281), los samuráis vieron que no podían depender de los remeros para que los rescataran cuando caían al agua o cuando tenían que sumergirse para rescatar a un samurái de rango superior. Asimismo, como señalan Ratti y Westbrook (1994: 327), "En Japón, los campos de batalla siempre atraviesan arroyos, ríos y lagos, y muchas batallas importantes tuvieron lugar cerca o en esas extensiones de agua que separan una isla de otra o varias islas del mar". Por tanto, desde los diversos clanes se impondría como estudio obligatorio para todos los samuráis las formas de natación con armadura.

Posteriormente, durante la "gran paz" del Periodo Tokugawa (1603-1867) se reestructuraron la mayoría de las Escuelas de Artes Marciales, "naciendo" diversas especialidades de la natación de combate (Suiei Jutsu), e incluso la equitación en el agua (Suiba Jutsu). Aunque también se trabajaron formas primitivas de buceo como aprovechamiento del medio, estas no serían casi usadas por los samurái sino por los ninja (los guerrilleros-espía de la época), ya que los primeros no las consideraban honorables.

En el combate acuático los samuráis comenzaban la instrucción del soldado por la natación, pasando posteriormente a la natación con armas pero sin armadura, y por último con armadura completa. También es cierto que todos los soldados no aprendían todas las técnicas, si no que dependiendo del nivel social del samurái se recibiría una instrucción u otra. Independientemente de esto, la natación era considerada dentro de las artes mayores del guerrero. Otro factor importante en la instrucción era el clan de pertenencia, ya que según fuese uno u otro se recibiría instrucción en distintos tipos de "especialidad acuática", si bien algunos samuráis realizaban peregrinajes para aprender los estilos de otras escuelas.

Los muchos siglos de luchas internas de Japón desarrollaron las formas acuáticas de lucha. Sería el largo periodo de aislacionismo del Periodo Tokugawa, su tardía entrada en la modernidad, así como su celo por las tradiciones, lo que permitiese que Occidente conociese algunas de estas formas de lucha. Las escuelas especializadas en la "natación de combate" tuvieron una gran proliferación en el Periodo Tokuwaga, cuando, a falta de guerras, el entrenamiento para el combate era un sustituto del propio combate. De estas escuelas han llegado hasta nuestros días noticias de algunas de ellas como la ryu Kobo de Kyushu, que perfeccionó notablemente estas formas de combate, o la ryu Suifu, que se especializó en nadar largas distancias. Incluso una de ellas, la ryu Yamanouchi, se hizo famosa por utilizar las armas de fuego mientras estaba en el agua. De hecho, este tipo de natación de combate, que incluía pruebas de destreza en el agua, aunque sin armadura, seguía estando
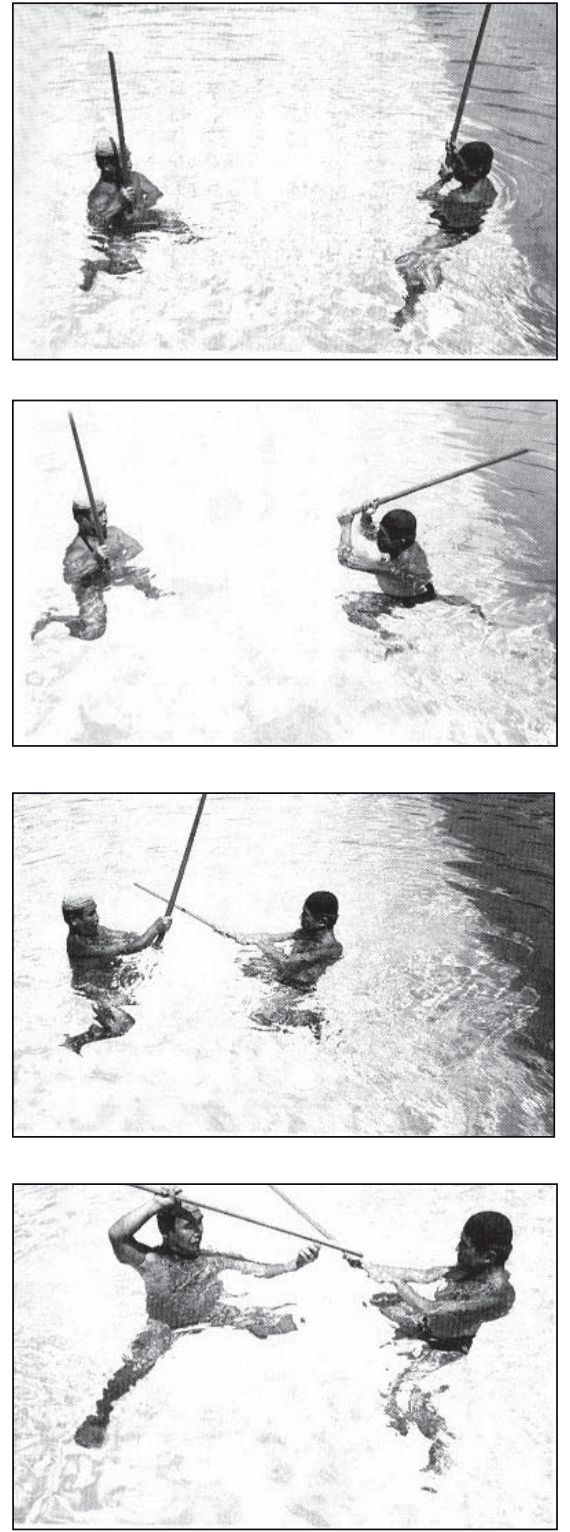

Figuras 2 a 5:

Secuencia de entrenamiento de combate de espada en el medio acuático. 
presente en ámbitos no militares incluso después de la Restauración Meiji (1868) (Ratti y Westbrook, 1994).

También propios de la época feudal japonesa serían los famosos "guerrilleros-espía”, los ninja. En su amplia instrucción una de sus especialidades era el buceo. Los ninja llevaban un tubo que les permitía respirar bajo el agua (como los actuales tubos de buceo), y usaban además pellejos de animales para poder permanecer sumergidos durante más tiempo y poder, por ejemplo, cruzar los fosos de los castillos sin ser vistos.

Actualmente, las formas tradicionales de natación de combate que perduran se ubican dentro del Bu Jutsu (técnicas antiguas del guerrero), quedando salvaguardadas dentro de determinadas Escuelas de Artes Marciales Tradicionales (como la Bujinkan de Ninjutsu del Maestro Maasaki Hatsumi) y en algunas asociaciones culturales, ya que estas no estudian un arte marcial concreto (como ocurre en Occidente) sino que pretenden lograr la formación completa del samurai (tanto sin armas como con armas, equitación, natación, escritura, etc.) o simplemente preservar una tradición. La Tabla I, basada en Ratti y Westbrook (1994), cita algunas de las diferentes escuelas de suie jutsu.

\begin{tabular}{|c|c|}
\hline Nombre de la escuela & Especialidad \\
\hline Ryu Kobori & Natación con armadura pesada \\
\hline Ryu Takeda & Natación con armadura pesada y en lagos \\
\hline Ryu Siufu & Nadar a largas distancias \\
\hline Ryu Yamanouchi & Uso de armas de fuego en el agua \\
\hline Ryu Shinden & Dominio de las corrientes de los ríos \\
\hline Ryu Mukai & Dominio de las corrientes de los ríos \\
\hline Ryu Sasanuma & Natación en lagos \\
\hline Ryu Kankai & Natación en mar abierto \\
\hline
\end{tabular}

Tabla 1: Distintas Escuelas (Ryu) japonesas de suie jutsu

Volviendo a retomar la historia occidental en el punto anterior, la Edad Media supondría un estancamiento, e incluso una involución, de la natación. Esto se debió principalmente al abandono que sufrió todo lo referente a la educación corporal en la Europa medieval, salvo en los países nórdicos que mantenían otros tipos de educación y cultura. Además, debido a las epidemias de peste se extendió la creencia de que el agua traía consigo enfermedades epidémicas (Lewin, 1979; Reyes, 1998). Por lo que se refiere al buceo militar, los españoles serían los primeros que en 1203 comenzaron a utilizar una especie de fuego de artificio en recipientes de barro que colocaban bajo el agua para incendiar las empalizadas que obstruían las entradas a los puertos y accesos marítimos. Posteriormente, Carlos I (1500-1558) utilizó buceadores militares para cruzar el río Elba en la toma de Muhlberg.

En cualquier caso, en Occidente este tipo de lucha acuática y su evolución en cuanto a la técnica corporal de realizarla no llegarían al mismo desarrollo que en Japón, y si en algún caso fue así se perdió en la historia, quedándonos únicamente algún relato épico como el sitio de Malta por los turcos (1565), donde buceadores turcos y malteses se enfrentaron en una sangrienta batalla marítima (Ivars y Rodríguez, 1987). 
Es en esta época del renacimiento cuando aparecen más referencias a la evolución del buceo. Así, el famoso Leonardo Da Vinci (1452-1519) realizaría diseños para mejorar el movimiento del hombre en el agua, así como y bosquejos sobre material para facilitar el buceo imitando la fisonomía de los patos y mejorando los elementos auxiliares de respiración. Igualmente, la natación reaparecerá como elemento de las actividades físicas, publicándose en 1538 el primer libro integro de natación titulado Colymbetes, Sive de arti natandis dialogus et festivus et iucundus lectu, del alemán Nicholas Giman (Iguaran, 1972).

Por último, la natación entendida como se hace hoy en día, tanto en su variante lúdica como de deporte de competición, no aparecerá hasta el siglo XIX, siendo Londres la ciudad donde se construye la primera piscina (1828) e Inglaterra la cuna de la natación moderna y competitiva (Reyes, 1998). El buceo en cambio irá evolucionando poco a poco, a medida que lo hacen los descubrimientos científicos y técnicos, pero siempre orientado hacia el trabajo bajo el agua, bien para la reparación de barcos, recuperación de tesoros y construcción de infraestructuras, o bien orientado hacia el combate militar.

Durante la primera mitad del s. XX se producirán dos hechos claves para el buceo. El primero llegaría de manos del Comandante Paul Gaston Yves Le Prior, uno de los primeros judokas franceses quien traería de Japón diversas enseñanzas y unirá en ellas sus dos pasiones, el buceo y el judo. Le Prieur patentó en 1933 el primer equipo de respiración autónoma y la máscara para poder mejorar la visión bajo el agua (Ivars y Rodríguez, 1987), siendo ésta la precursora de las "actuales gafas de buceo". El segundo hecho clave provendrá igualmente de otro militar, el entonces Teniente de Navío Jacques Yves Cousteau quien en 1942 inventaría el otro elemento que revolucionaría el buceo: la escafandra con regulador. Esto permitiría a los buzos de la época poder descender a profundidades hasta entonces inimaginables y, además, a la larga produciría la "popularización y deportivización" del buceo. Por todo ello será Francia uno de los primeros países en introducir este tipo de luchas acuáticas en su Ejército y posteriormente se le irán uniendo diversos países entre ellos Estados Unidos, Gran Bretaña, etc.

A partir de aquí sólo se puede hablar de la evolución técnica de los medios de buceo, de la natación y de los medios específicos de combate (técnicos y humanos) desarrollados durante y a partir de la Segunda Guerra Mundial, y de la consecuente evolución de las tácticas usadas en el combate. Asimismo se popularizarán muchos aspectos ligados al medio acuático, como la natación y, en las últimas décadas, el buceo, siendo en la actualidad un medio de gran complejidad para su dominio pero muy extendido en su variante lúdico-deportiva, debido a la gran facilidad existente hoy en día para poder aprender a nadar y a bucear.

\section{El combate en el medio acuático en los ejércitos modernos}

Los progresos técnicos derivados de la I Guerra Mundial favorecieron que el mundo del buceo militar experimentase un gran impulso, sobre todo en cuanto a los equipos de circuito cerrado (aquellos que no emiten ningún gas al exterior del equipo). Posteriormente, la II Guerra Mundial sería el otro gran suceso impulsor de esta materia, en especial el ejército italiano con la creación de unos torpedos tripulados por dos hombres que podían acercarse al objetivo bajo el agua desde largas distancias. Con ellos nacerán los "hom-
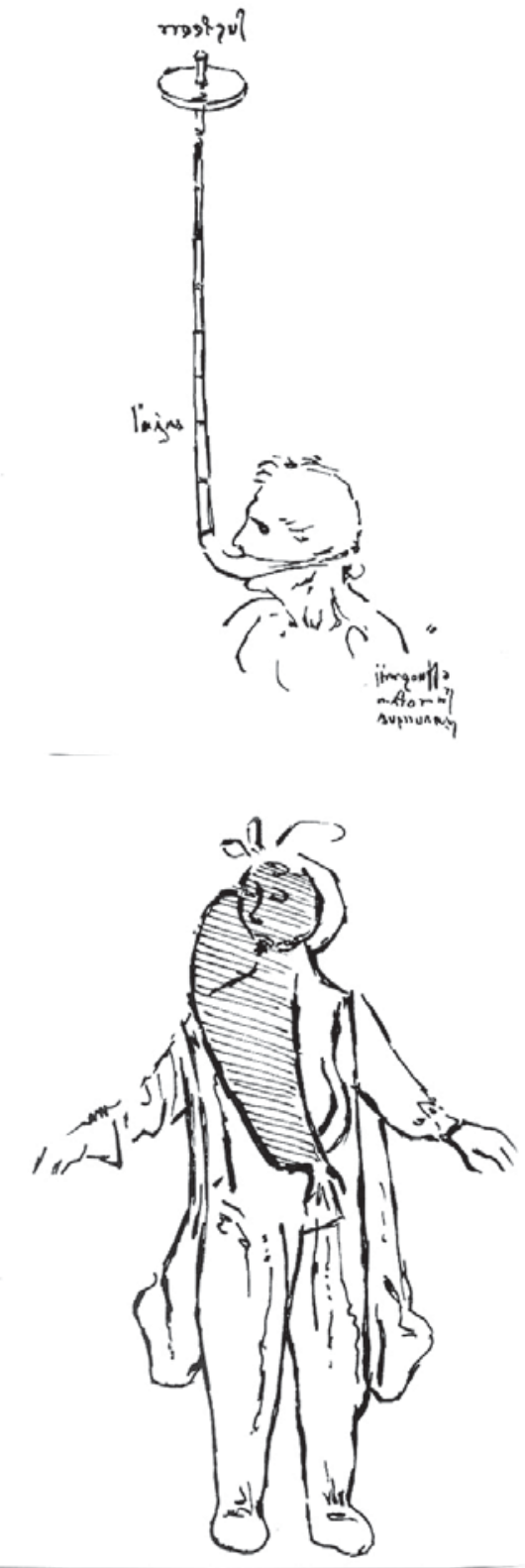

Figuras 6 y 7 :

Diseños originales de Leonardo Da Vinci para facilitar el buceo. 
bres-rana" que tantos éxitos tuvieron en la preparación de desembarcos en las costas enemigas, volando con explosivos los obstáculos preparados para evitar el paso de embarcaciones. Esta denominación de hombre rana-nace del parecido del traje y las aletas con las ancas de las ranas, y ninguna otra denominación ha podido con la establecida en la II Guerra Mundial por los periodistas y escritores de la época. Será en esa época cuando se cambie la concepción del movimiento acuático y el hombre en vez de andar, trepar o arrastrarse por el fondo se dedique a imitar a los peces y a nadar entre dos aguas, forma de desplazamiento que sigue usándose en la actualidad.

Como resulta conocido, podemos tomar como cuna de las artes marciales en Occidente a Inglaterra y posteriormente a países como Francia o Estados Unidos. Respecto al tema que ocupa a este artículo, y como ya se ha visto anteriormente, será Francia la que desarrolle el buceo militar y lo una al combate acuático. Este país cuenta con una Unidad encargada de impartir instrucción de combate cuerpo a cuerpo en Antibes, que realiza las mismas funciones que en España la Escuela Central de Educación Física de Toledo. Dicha Unidad imparte igualmente cursos específicos de combate cuerpo a cuerpo.

En otros países, como Estados Unidos, la formación de combate cuerpo a cuerpo es inherente a la formación militar, y se enseña en diversos campos: Defensa Personal para todo militar, Close Combat para ciertas unidades de combate (Rangers, Boinas Verdes, etc.), y cursos especiales de combate en varias escuelas (SFAT, SCARS,...) orientados a campos especiales. En el caso del combate acuático existen dos unidades elites en el mundo, los SEAL's americanos y el SAS's británico. Ambos cuentan con una gran experiencia de combate real y de hecho sus métodos de instrucción no son muy difundidos.

Todo esto demuestra la importancia que tiene el combate acuático en las unidades "especiales" de algunos ejércitos de primer orden. En otros ejércitos de distintos países, evidentemente, se trabajan igualmente estos aspectos, que aquí no detallaremos ya que no pretendemos realizar un estudio pormenorizado de la materia, sino más bien dar una visión global del combate en el medio acuático.

Por lo que respecta al Ejército de Tierra español, una de las primeras noticias que se tiene de la natación de combate será dentro del $1^{\circ}$ Curso de Guerrilleros (1956), en el que ya existía una fase de agua, aunque no con la especialización de hoy en día. Posteriormente será en 1959 cuando la Armada comience a impartir cursos para el resto del personal de las Fuerzas Armadas. Dentro del Ejército de Tierra la primera unidad encargada del buceo y de sus aplicaciones militares fue el Regimiento de Pontoneros y Especialidades de Ingenieros n ${ }^{\circ} 12$, allí nacería en 1972 el germen de las actividades subacuaticas en el Ejército de Tierra. Se realizaron ocho cursos de buceo experimentales dentro de la $5^{\circ}$ Región Militar y ya en el año 1974 se realiza el $1^{\circ}$ Curso Experimental de Zapador Anfibio (para suboficiales y cabos $1^{\circ}$ ). Esto fue posible gracias al entonces Capitán Manuel de la Figuera Aranda, por aquellas fechas Instructor Nacional de Buceo y que posteriormente llegaría a ser Presidente de la Federación Española de Actividades Subacuaticas.

Más tarde nacería la Sección de Actividades Anfibias (S.A.A.) (19772000), sita en Monzalbarba (Zaragoza) y dependiente de la Academia de Ingenieros del Ejército de Tierra (ACING) la cual formó hasta su disolución a más de 2.500 buceadores del Ejército y otros organismos. Ya en esos primeros años se realizaron intercambios con otros países, como el realizado con el SEAL TEAM 2 (USA) en el año 1976, en el que se pudo ver, como cita el informe de la fecha, que "sí bien entonces nuestro material era superior al de 
ellos, ellos tenían mucha más experiencia en las formas propias del combate anfibio" (Informe S.A.A, 1976).

Sin los primeros pasos de la S.A.A. y su consolidación en el mundo del buceo a través de los cursos de Zapador Anfibio, Buceador de Asalto y Buceador de Apoyo, posteriormente no hubiera podido ser desarrollada esta tarea de la forma que se hizo en el Ejército de Tierra. Tras la disolución de la S.A.A. en el año 2000 pasa a coger su testigo la Unidad Escuela de Buceo, integrada en el Regimiento de Pontoneros y Especialidades de Ingenieros $n^{\circ}$ 12. Dicha unidad es la encargada hoy en día de la enseñanza del buceo en el E.T. y además asume otros contenidos como son:

- Perfeccionamiento de las técnicas de natación de combate y buceo.

- Perfeccionamiento y aplicación de estas al combate.

- Información sobre nuevas técnicas de buceo.

- Ampliación de las formas de trabajo subacuatico.

- Investigación y experimentación sobre el material y el armamento subacuatico.

- Redacción y propuesta de normas de uso de los buceadores de asalto y zapadores anfibios.

- Otros (colaboraciones con entidades civiles en estudios, expediciones, etc.).

(OR5-404, Zapador Anfibio, procedimiento de empleo, 1999)

Dentro de estos cometidos, este artículo hará hincapié en el combate cuerpo a cuerpo en el medio acuático, tanto en la superficie como en profundidad. En este tipo de combate, la Unidad Escuela de Buceo del Ejército de Tierra sigue una progresión y metodología básica. En primer lugar, el soldado debe saber nadar para posteriormente aprender la aplicación militar de la natación, es decir, la natación de combate. Posteriormente, y ya dentro de la Escuela de Buceo, se aprenden las técnicas básicas de combate en superficie, finalizando con las técnicas de combate en profundidad tanto sin equipo de respiración autónoma como con él, siendo estas específicas de buceadores.

La natación de combate trabaja aspectos tan importantes como la supervivencia en el mismo con las manos y/o pies atados, la evacuación de un compañero herido y, obviamente, el combate, debiendo ser capaz el soldado de apuntar con el arma mientras realiza movimiento de avance o retroceso dentro del medio. Todo lo anterior es realizado con el equipo de combate reglamentario (uniforme, botas, mochila de combate y armamento).

\section{Factores determinantes del combate cuerpo a cuerpo en el medio acuático}

Dentro de los aspectos técnicos del combate cuerpo a cuerpo en el medio acuático, tanto en superficie como en profundidad, debemos tener en cuenta una serie de factores:

- Intrínsecos del medio en el que se desarrolla, en este caso el acuático.

- Ligados a la capacitación del combatiente.

- Concretos de la misión a desarrollar.

El combate en superficie va a surgir en momentos muy delicados en las operaciones anfibias, habitualmente al abandonar el medio acuático o al in-

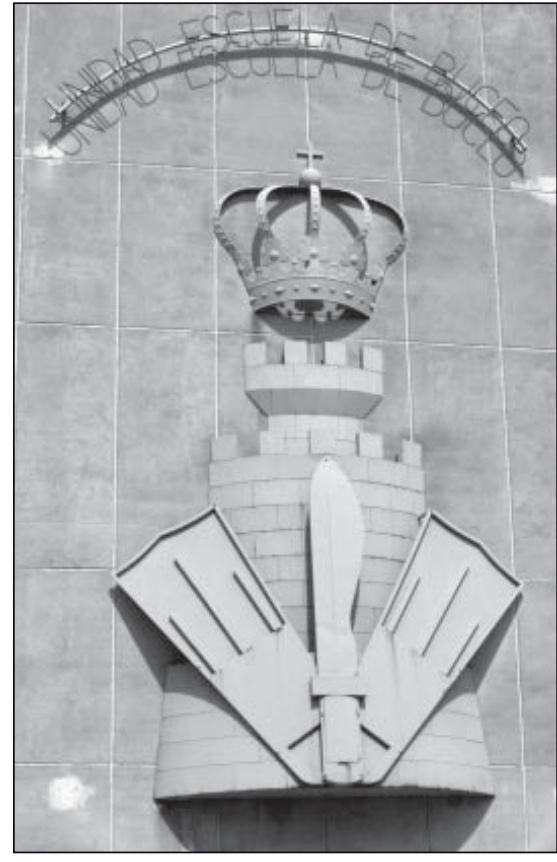

Figura 8:

Escudo de la Unidad Escuela de Buceo del Ejército de Tierra Español. 
tentar volver a él. En esos momentos el buceador se puede encontrar en desventaja ya que abandona su medio, el agua, para volver a tierra. Para las tropas terrestres ocurre a la inversa, este momento se puede producir al intentar vadear un curso de agua, que no es su medio habitual, por un encuentro con tropas anfibias saliendo o entrando al agua, o simplemente por que estén defendiendo una posición cercana al medio acuático (puntes, presas, etc.).

Las formas de combate en profundidad, en cambio, van a ir orientadas principalmente a unidades de Operaciones Especiales, Buceadores de Asalto y Zapadores Anfibios, ya que ellos van a tener que desenvolverse en el medio acuático, especialmente los buceadores. También ciertas unidades deben de conocer, aunque no con tanta profundidad, el combate en este medio por motivo de las misiones especificas que se les asigne, como pueden ser reconocimientos, protección de puntos sensibles (puentes, presas, etc.) cercanos al agua o bien por la destrucción de estos.

\section{Intrínsecos del medio acuático}

Existen muchos factores que limitan la presencia del hombre en el medio acuático. Entre los mismos, la imposibilidad de respirar en inmersión, las dificultades para desplazarse con fluidez, e incluso la alteración sentidos como el equilibrio o la vista, ya que el oído y el ojo humanos no responden satisfactoriamente en este medio. Existen, asimismo, una serie de factores intrínsecos o propios del medio acuático que van a condicionar la presencia del hombre en el mismo, y particularmente sus posibilidades de combate. Dentro de estos factores intrínsecos deben considerarse fundamentalmente los siguientes:

- La profundidad y naturaleza del fondo.

- La temperatura del agua.

- La presencia o ausencia de corrientes marítimas y/o fluviales

- La flotabilidad.

- La resistencia del agua.

La profundidad es la altura cubierta por el agua que existe desde el fondo hasta la masa de aire. En el caso del combate acuático caso se van a considerar varias alturas (se presenta una clasificación-tipo de alturas, que, en cualquier caso, dependerá de las dimensiones antropométricas del individuo):

- A) De 20 a 30 cm., es decir, por debajo de la rodilla. En este caso, el combate no puede considerarse combate acuático como tal.

- B) De 30 a 100 cm., aproximadamente entre la rodilla y la cintura. Se estaría hablando de combate en aguas poco profundas o superficiales.

- C) De 100 a 150 cm., cuando el agua cubre por encima de la cintura y se consigue un avance más rápido nadando. En esta altura comenzaría el combate acuático, siendo la aplicación de las técnicas de la parte superior del tronco igual que en el combate terrestre.

- D) De 150 a $180 \mathrm{~cm}$., cuando el agua cubre aproximadamente por el pecho o por encima del mismo, pero la persona hace pie. A dichas alturas es cuando el combate es totalmente acuático, ya que los combatientes, aun tocando fondo, realizaran muchas acciones sin apoyarse en él.

- E) Por encima de $180 \mathrm{~cm}$., cuando la persona para respirar no toca el fondo. 


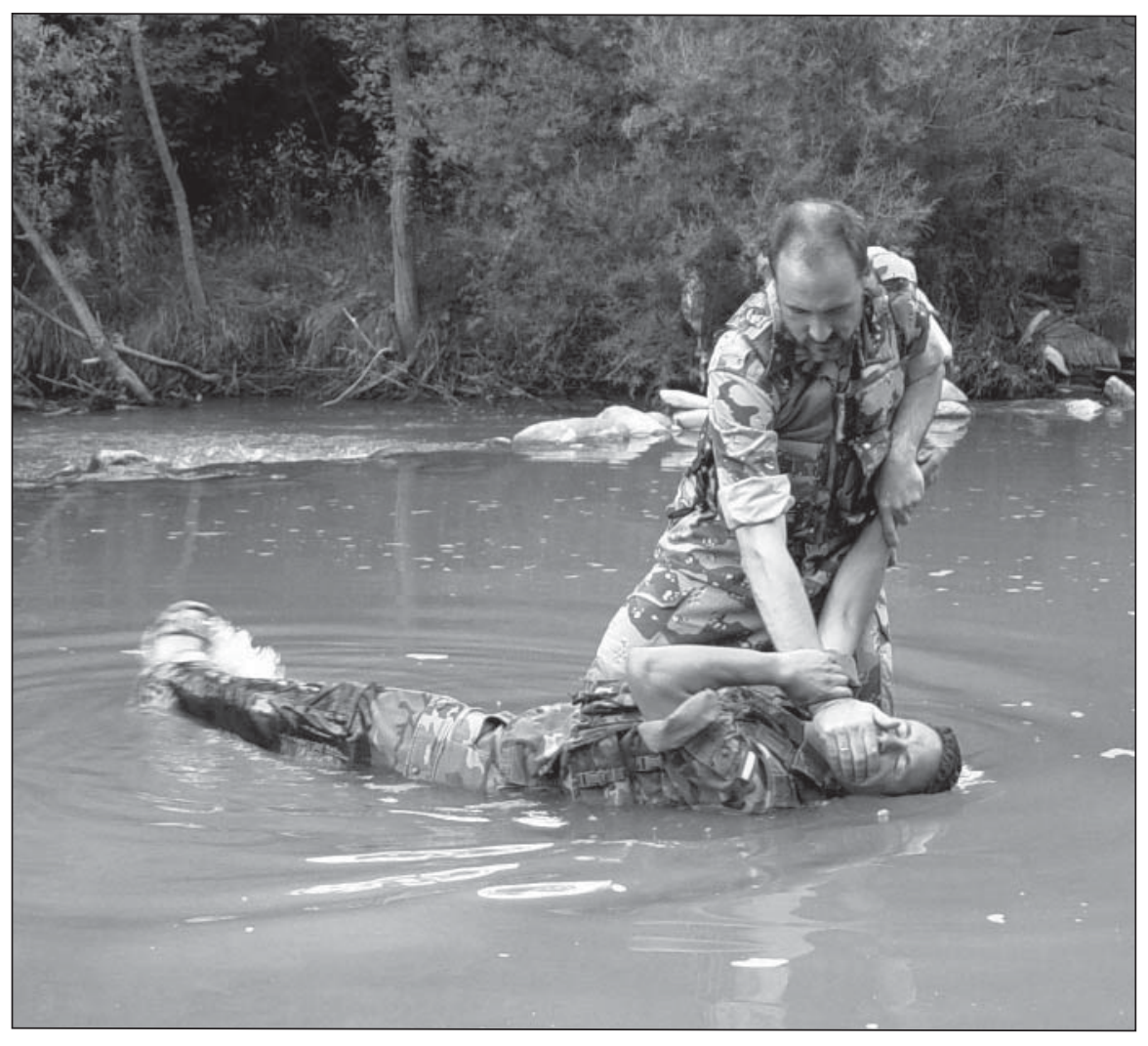

La profundidad va a ser un factor importante a la hora de dar seguridad a personas que no están habituadas al medio acuático, ya que si no se puede tocar el fondo -coloquialmente, si no "se hace pie"- aumenta la sensación inseguridad pudiendo llegar incluso al pánico. Igualmente, la altura del cuerpo del combatiente a la que llegue el agua condiciona las defensas o ataques a realizar. Así, cuando el agua está por encima de la cintura de un sujeto, su capacidad para desplazarse en bipedestación es prácticamente nula, obligando al combatiente a nadar para poder desplazarse. De igual forma, la naturaleza del fondo facilitará o dificultará los desplazamientos, ya que no es lo mismo el apoyo en roca, en arena o en un terreno fangoso. Como señala Lumbreras (2003:49): “... la previsión de la posición estable es fundamental, ya que el agua y su fondo irregular dificultan enormemente el equilibrio y la movilidad".

La naturaleza del fondo cobra una especial relevancia en las tres primeras situaciones descritas en la clasificación anterior (hasta 1'50 metros). En esos casos, el combatiente normalmente se desplaza andando y necesita asegurar su posición manteniendo el equilibrio, tanto en los desplazamientos como en la lucha. El hecho de tener un sólido apoyo en el fondo va a marcar la diferencia entre lo que es realmente el combate acuático y lo que sería la lucha terrestre dentro del agua (altura inferior a 1'50 metros). Hasta esta profundidad se considera el combate como una aplicación terrestre, en la que el agua limita los desplazamientos y movimientos del tren inferior, pero no afecta en general a las técnicas, salvo, como puede deducirse fácilmente, a los golpes con las piernas y a las proyecciones de manera fundamental.

La gran diferencia entre el combate a esta escasa profundidad y la superior a 1'50 metros va a consistir en la necesidad de desplazarse mediante las formas propias de la natación de combate. Es en esta situación donde comienza a desarrollarse verdaderamente el combate acuático y donde las

\section{Figura 9:}

Ejemplo de lucha en aguas de profundidad menor a $30 \mathrm{~cm}$.

Fotografía cedida por la Revista Soldiers (J. Vicente Lumbreras) 


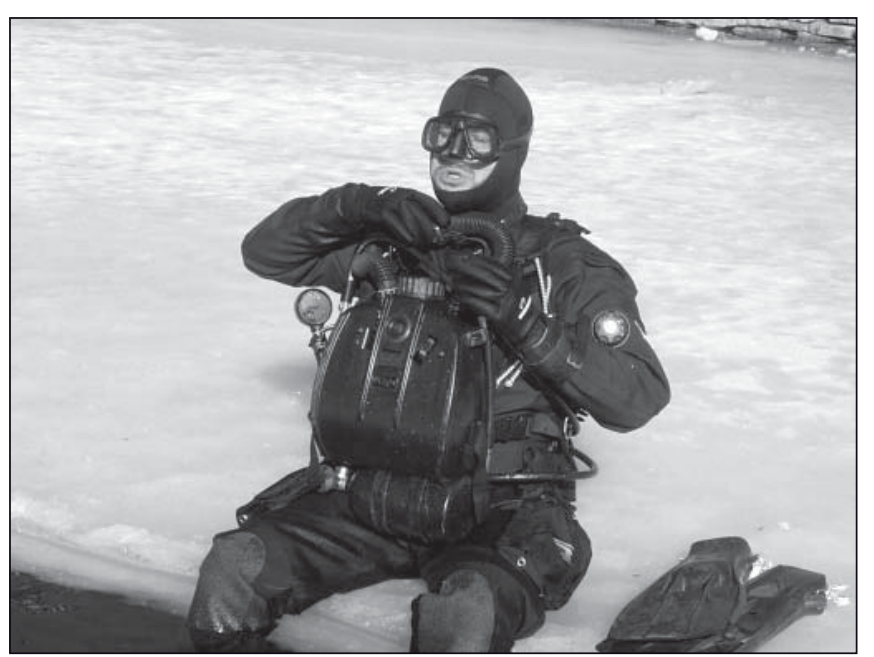

Figura 10:

Practica de buceo en hielo con Equipo de Circuito Cerrado. El equipo de buceo permite la supervivencia del buceador en el medio acuático, a la vez que condiciona las posibilidades de combate del soldado. Fotografía cedida por la Unidad Escuela de Buceo técnicas de combate ya no son las mismas que en tierra sino que deben ser "modificadas" para obtener de ellas una mayor eficacia. La preparación para el combate acuático es, pues, una labor especializada. Según el Manual de Zapador Anfibio del Ejército Español (1999: cap. 1, 10) "todos aquellos trabajos de ingenieros que se realicen en aguas interiores a una profundidad mayor de 1'5 metros deberán ser realizados por soldados con la aptitud de buceador de apoyo como mínimo y estarán dirigidos por un zapador anfibio". Por ello las unidades normales se verán poco involucradas en el medio acuático salvo en tareas de vigilancia o montaje de puentes, pontones u otras instalaciones cercanas a ríos, pantanos o costas.

Por otro lado, ha de considerarse la temperatura del agua. En el mar, esta temperatura del agua se encuentra habitualmente entre $15^{\circ}$ y $30^{\circ} \mathrm{C}$, siendo algo menor en ríos y pantanos. En cualquier caso, la temperatura del agua va a ser siempre menor que la del organismo humano $\left(36^{\circ}-37^{\circ} \mathrm{C}\right)$, por lo que, dependiendo de esta, se corre el riesgo de sufrir una hipotermia al realizar una inmersión prolongada. Si el cambio de temperatura es demasiado brusco puede llegar a provocarse un schok hipotérmico, situación muy peligrosa dentro del agua. La temperatura del agua, igualmente, condicionará la capacidad de reacción del combatiente, su movilidad e incluso su espíritu de supervivencia, pudiendo incluso hacerle caer en el abandono.

En lo que respecta a la presencia de corrientes marinas o fluviales, el empuje del agua va a ser muy importante, ya que tenerlas a favor o en contra puede decantar el combate en uno u otro sentido. Parafraseando la vieja sentencia que dice que "no se puede nadar contra corriente", tampoco se debe "combatir contra corriente", ya que cualquier aplicación de fuerza quedará notablemente debilitada.

En cuarto lugar, es necesario referirse a la flotabilidad, que depende tanto del medio como del cuerpo que se sumerge en el mismo. A efectos prácticos, la flotabilidad se traduce en tres situaciones:

- Flotabilidad positiva: en la que el cuerpo tiende a ascender, ya que el empuje hidrostático sobre el cuerpo es mayor que la acción de la gravedad sobre el mismo.

- Flotabilidad neutra: el cuerpo tiene equilibrada la acción de la gravedad con el empuje hidrostático y por lo tanto ni asciende ni desciende.

- Flotabilidad negativa: el cuerpo desciende debido a que la acción del empuje hidrostático es menor que la de la acción de la gravedad.

Dichas situaciones tienen importantes consecuencias ya que van a condicionar el tipo de combate a desarrollar, bien en superficie o en profundidad. Durante el combate se debe tener en cuenta la flotabilidad de los dos adversarios, ya que un combatiente no podrá arrastrar al fondo a otro si este tiene una gran flotabilidad (propia o adquirida por medios específicos).

Por último, la resistencia del agua hacia el cuerpo humano es un factor importante ya que puede facilitar y dificultar los movimientos corporales. Existen tres tipos fundamentales de resistencia. La primera, y más importante, es la resistencia de forma o presión. Debido a ella, cuando el cuerpo se desplaza en superficie, se crea un gradiente de alta presión delante de él y otro de baja detrás. Dicho gradiente ejerce una resistencia al desplazamiento 
en superficie. La segunda resistencia a tener en cuenta es la debida al oleaje, producida por los movimientos interfase entre el aire y el agua. Esta resistencia no afecta a los movimientos subacuaticos de los buceadores. Por último la resistencia por fricción o debida a arrastre viscoso, su valor depende de la cantidad de superficie en contacto con el agua, de la viscosidad del agua y del coeficiente de fricción del material en contacto con el agua.

El conjunto de factores intrínsecos antecitados tienen unas importantes consecuencias sobre las funciones vitales, sensoriales y motrices del combatiente, siendo estas las principales:

- La respiración se altera de un modo notable, modificándose e incluso llegando a desaparecer al sumergirse completamente en el agua si no se lleva equipo de respiración autónoma. Durante acciones de nado, el ritmo respiratorio facilitará el traslado del cuerpo y lo preparará para una posible lucha en superficie. En el caso de acciones de buceo la respiración cobra aún mayor importancia, ya que si el ritmo respiratorio es muy elevado el combatiente agotará demasiado pronto la reserva de aire de su botella, con lo cual deberá abandonar la inmersión. Además, se corre el riesgo de no ventilar correctamente, haciendo que los pulmones se saturen de $\mathrm{CO}_{2}$ y que sea necesario aumentar el consumo de aire. En este caso se entra en un circulo vicioso en el que cada vez se ventila peor se consume más oxígeno, acelerándose asimismo el ritmo cardiaco. La situación descrita puede darse en buceadores noveles y también en el desarrollo de un combate prolongado (mayor de 30 o 40 segundos) e intenso. No entraremos en más detalles en este campo con respecto a otros tipos de cargas para los equipos, como pueden ser el oxígeno (con los equipos de circuito cerrado) o las mezclas nitrox (oxigeno mezclado con nitrógeno), que requerirían un estudio más detallado.

- La visión del combatiente se vera afectada desde un primer momento. Cuando el cuerpo se sumerge la primera impresión es de visibilidad nula, y luego todo aparece borroso. Si la inmersión se produce en agua de mar, la presencia de la sal casi impide al personal no acostumbrado que los ojos permanezcan abiertos. En cambio, cuando se porta mascara de buceo, los objetos aparentan tener un tamaño mayor, sobre $4 / 3$ del original, y encontrarse a una distancia menor, sobre $3 / 4$ de la real. Igualmente, dependiendo de la profundidad, los colores se van perdiendo al disminuir la intensidad de la luz. Por último, el radio de visibilidad disminuye con la profundidad y contaminación del agua, siendo casi nulo al realizar inmersiones en ríos y pantanos, debiéndose esto a la gran cantidad de partículas en suspensión.

- La audición se distorsiona estando en superficie, y los ruidos exteriores desaparecen si se está sumergido. En cambio, dentro del agua los ruidos se transmiten mucho más rápidamente que en el exterior y resulta difícil localizar el foco del sonido. Por tanto, debajo del agua desaparece la comunicación verbal y se usa un lenguaje de señas convenido.

- La presión dentro del agua es un factor muy importante para los buceadores y por lo tanto para el combate subacuático. Esta presión va a afectar al organismo del buceador tanto al ascender como sobre todo al descender, cuando esta aumenta. Dicha presión afectará sobre todo a oídos, pulmones, senos paranasales, y de forma excepcional al aparato digestivo o a una caries (burbujas de aire atrapadas). 
- La acción de la gravedad queda distorsionada dentro del agua, pudiendo producirse dos efectos muy distintos: a) La casi desaparición de sus efectos (por la acción de los equipos de buceo), y b) El incremento de dichos efectos por el mayor peso de la ropa y el equipo de combate al mojarse.

- En inmersión, es mucho más difícil mantener una posición estable y un buen equilibrio. El equilibrio es la base del movimiento acuático, al igual que en tierra.

- Aumenta la dificultad para precisar un objetivo concreto, ya que el agua y el propio movimiento de reacción del cuerpo hacen que los golpes se desvíen.

- La velocidad de los movimientos se ve reducida por la acción de la mayor densidad del agua con respecto al aire. Por ello se ven afectadas tanto la velocidad de desplazamientos, la de reacción y por supuesto la velocidad gestual.

- Las exigencias de fuerza en el medio acuático van a ser mayores que en el medio terrestre, debido a la mayor resistencia exterior que este ofrece. Ello obliga al combatiente a aplicar una fuerza mucho mayor dentro del agua para obtener los mismos resultados que fuera de ella, tanto a la hora de golpear como de simplemente desplazarse.

- La resistencia, entendida como la capacidad del sujeto para soportar la fatiga, también va a ser menor debido a lo inusual del medio. La resistencia aeróbica permitirá fundamentalmente mantener el organismo a flote y soportar los traslados del cuerpo. La resistencia anaeróbica, en cambio, va a ser la que posibilita al combatiente sobrevivir en el combate, ya que en igualdad de "condiciones técnicas" una mayor capacidad para mantener el esfuerzo puntual de la lucha puede facilitar la derrota del enemigo por agotamiento.

- La agilidad, por último, también se ve muy afectada en el medio acuático. Con la denominación de "soltura acuática" se hace referencia a esta capacidad de "ser ágil" en el agua, siendo este un aspecto muy importante para el desplazamiento y el combate en el medio acuático.

Como se ha señalado, todo lo anteriormente expuesto afecta al combatiente, de modo que el combatiente debe ser capaz de familiarizarse con las particularidades del medio acuático, superar las dificultades que este le impone y adaptar las formas de lucha terrestres para su uso en el agua.

\section{Ligados a la capacitación del combatiente}

La respuesta y adaptación del combatiente ante el medio acuático depende fundamentalmente de su instrucción. Así, podemos clasificar a los combatientes en cuatro tipos principales:

1. Aquellos que carecen de instrucción en el medio acuático, independientemente de que sepan nadar o no. Unidades normales de cualquier especialidad.

2. Aquellos que por sus cometidos tienen una instrucción básica para sobrevivir en el medio acuático. Todos aquellos que realizan trabajos próximos al agua como por ejemplo los pontoneros (soldados de ingenieros que construyen puentes). 
3. Aquellos que tienen una destreza alta en el medio acuático debido a los cometidos especiales que desempeñan. Patrullas de reconocimiento, paracaidistas, operaciones especiales.

4. Aquellos que trabajan específicamente en este medio. Equipos de agua de operaciones especiales, operaciones anfibias, zapadores anfibios, etc.

Dependiendo del grado de instrucción, por tanto, el combatiente podrá desarrollar un tipo de misiones u otras, y sus posibilidades de supervivencia en un combate en el medio acuático serán muy distintas. En algunos casos nos encontraremos con personal altamente cualificado, mientras que en otras ocasiones la capacidad de desenvolvimiento del combatiente en el medio acuático será prácticamente nula.

\section{Concretos de la misión a desarrollar}

La misión a desarrollar es, al fin y al cabo, la que va a marcar el tipo de combate que se puede llegar a producirse. Normalmente el combate acuático se producirá por alguno de los siguientes motivos:

- Caída fortuita al agua del combatiente, bien porque se arrastra al enemigo o por que él nos arrastra.

- Salida en fuerza de una zona, produciéndose la caída anterior.

- Entrada o salida del agua por parte de un equipo.

- Encuentro entre equipos enemigos bajo el agua o en la superficie del agua.

En los casos citados debe tenerse en cuenta que cuando los equipos de combate realizan este tipo de acciones, priman ante todo el silencio y la ocultación. Por ello, siempre se usaran técnicas silenciosas y se huirá del combate abierto como tal. En los casos más desfavorables no quedará más remedio que la lucha, debiendo ser esta rápida y mortal.

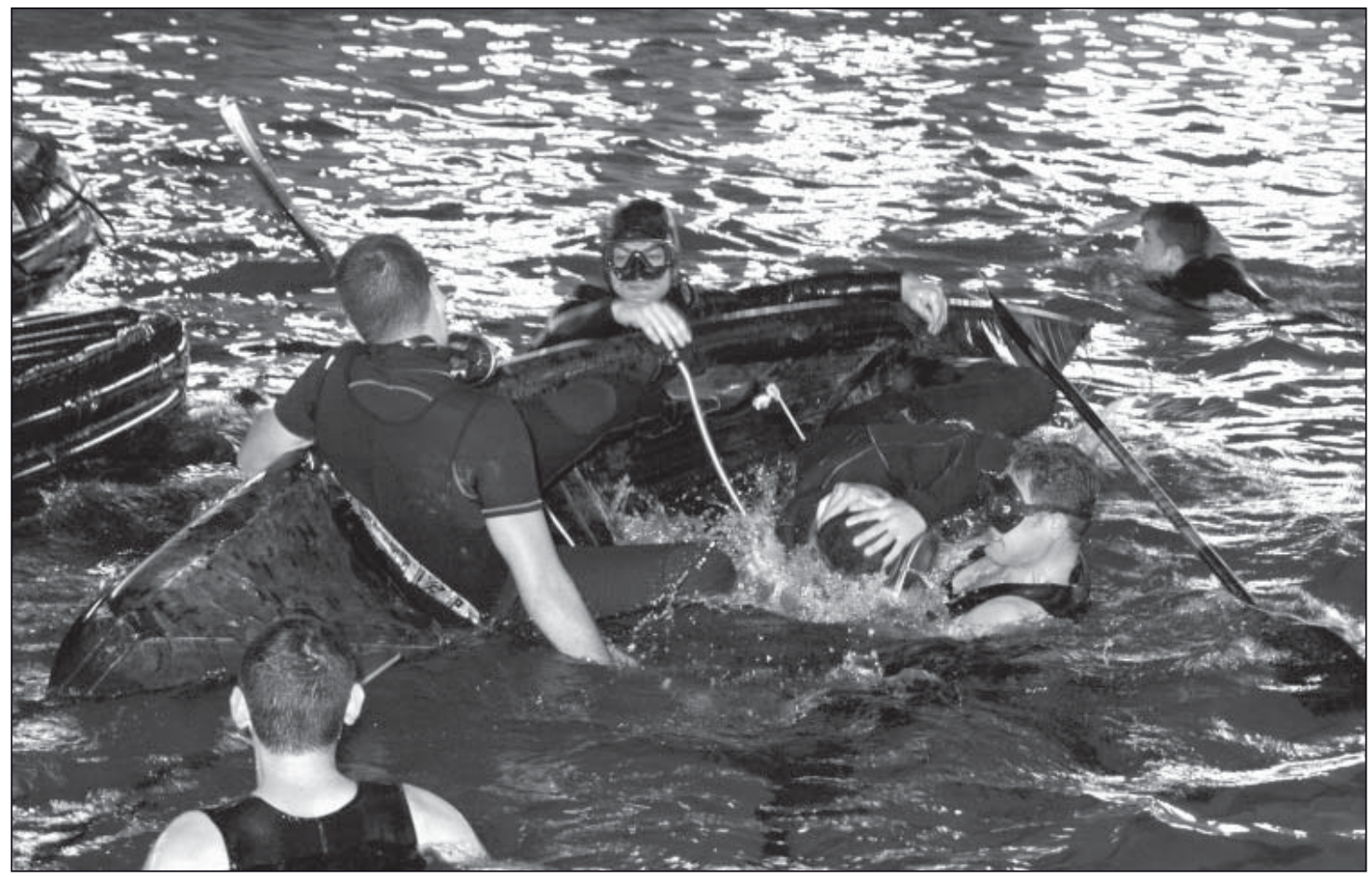

Figura 11:

Simulación de un asalto a una embarcación.

Práctica realizada durante el Curso de Buceador de Asalto del Ejército de Tierra. 


\section{Aspectos técnicos del combate cuerpo a cuerpo en el medio acuático}

A continuación se describen los grupos de elementos técnicos propios de las formas de combate acuático cuerpo a cuerpo. No pretendemos realizar un estudio pormenorizado de las distintas técnicas, sino particularmente algunas consideraciones generales sobre sus fundamentos de ejecución.

En el combate acuático, las primeras técnicas que deben sufrir modificaciones son aquellas que tienen como elementos fundamentales las armas naturales del cuerpo, es decir los golpes, las presiones, las luxaciones y las estrangulaciones. Como puede apreciarse, entre estos bloques técnicos no figuran las formas de proyectar al adversario. Ello es debido a que las proyecciones no tienen el mismo efecto dentro del agua que en tierra. Las proyecciones en tierra tienen como finalidad golpear al enemigo contra el suelo para provocarle diversos tipos de daños por el impacto. Sin embargo, en el agua este efecto no se produce, consiguiéndose únicamente un cambio de posiciones entre los adversarios, que no obstante puede ser de gran utilidad para aplicar otro tipo de técnicas o encadenamientos de movimientos.

\section{El combate acuático en superficie}

\section{Golpes y presiones}

Las formas de golpeo en la superficie del agua deben limitarse a buscar el impacto en las zonas del cuerpo del adversario que también estén fuera del agua. Todo aquel golpe que se produce cambiando de medio (aire-agua o agua-aire) pierde precisión y potencia. Como elemento primario de cualquier combate, los golpes y presiones deben aplicarse únicamente en las distancias cuerpo a cuerpo, obviándose las distancias media y larga. Esto es así ya que el golpeo a estas distancias media y larga pierde mucha potencia y precisión, careciendo entonces de efectividad, además de la posible pérdida del equilibrio por parte del atacante. Por ello los golpes principales que se van a poder ejecutar a este nivel van a ser los siguientes:

- Golpes con los puños.

- Golpes con los cantos o la base de las manos.

- Golpes con los dedos.

- Golpes con los codos o los antebrazos.

- Golpes con la cabeza.

En los golpes, dependiendo de la instrucción del combatiente, primará la contundencia. Las personas menos fuertes, tenderán a golpear normalmente con la base de las manos, codos o cabeza, obviando el resto de golpes salvo casos muy concretos. Los objetivos fundamentales de todos estos golpes van a ser la cabeza y el cuello, y particularmente sus múltiples distintos puntos vitales o vulnerables:

- Los ojos. Con lo que se le limitará o impedirá la visión al enemigo.

- La nariz. Provocándose desde efectos leves, como el desvanecimiento, a efectos graves como son la rotura del tabique nasal o incluso la afectación del bulbo raquídeo. 
- La boca. Se producen efectos muy dolorosos, comprendiendo desde la hemorragia a lesiones en los maxilares o pérdida de piezas dentales. Se trata de una lesión muy grave para los buceadores ya que les impedirá respirar correctamente bajo el agua.

- El cuello. Dificultando la oxigenación del cerebro bien por falta de aire (traquea o laringe) o por falta de sangre (golpe en los laterales, artería carótida).

- Los oídos. Afectando al equilibrio y a la posibilidad de realizar inmersiones posteriores. El golpe al oído puede ir dirigido al pabellón auricular, localizado en la misma oreja, o al nervio aurículo-temporal, localizado justamente delante del lóbulo auricular. Este segundo es un golpe mucho más doloroso pero más difícil de aplicar con contundencia.

- Las vértebras cervicales. Puede llegar a ocasionarse desde un desvanecimiento a la muerte si el golpe es suficientemente contundente.

- Las clavículas. La rotura de las clavículas es de gran eficacia para inutilizar los brazos del adversario y limitar su capacidad para mantenerse a flote.

En lo que se refiere a las presiones, su aplicación a determinados puntos vulnerables va a poder realizarse del mismo modo que en tierra, teniendo como principal limitación la que imponga el equipo que porte el enemigo y el que portemos nosotros mismos. La altura a la que se encuentren estos puntos vitales es un elemento relevante. Así, siguiendo la clasificación que cita Planellas (1995), el nivel Jodan (de los hombros a la cabeza) tiene más de veinte puntos vulnerables dignos de ser atacados, todos ellos con efectos que oscilan desde las molestias más leves hasta las más letales en algunos casos. Los otros dos niveles, Chudan (zona media del cuerpo, del cuello a la cintura) y Gedan (zona baja del cuerpo, de cintura hasta los pies) son menos interesantes en el trabajo de golpes en la superficie del medio acuático, por ser de más difícil acceso.

\section{Controles}

Por lo que se refiere a los controles, debe destacarse la gran importancia de las piernas en el combate acuático. Como bien señala el gran judoka Katsuhiko Kashiwazaki (1993: 27), y aplicando a nuestro campo una máxima del judo suelo "en las manos de un verdadero especialista, son las piernas las que dan la impresión de tenerte completamente atrapado". De ellas se servirá el combatiente para fijar a su adversario, moverlo en una dirección o en otra (usando el giro de su cadera) o en un momento dado para apartarlo o hundirlo. Siendo irrelevantes los controles habituales que se practican en tierra, ya que falta el elemento principal, el suelo, por lo que no se puede realizar presiones contra él.

En la acción de apartar, al igual que sucede con los golpes, es necesario aplicar la presión en los lugares adecuados siendo estos los siguientes:

- Testículos. Logrando con ello, como mínimo, incapacitar temporalmente al adversario.

- Boca del estomago. El objetivo será, al menos, afectar a su ritmo respiratorio a la vez que se le desplaza.

- Debajo del ombligo. En este caso se busca el desvanecimiento, si existe suficiente potencia, o en su defecto el desplazamiento del enemigo. 
Figura 12:

Ashi-garami. El uso de las piernas como elemento de sujeción del cuerpo del adversario es fundamental para la aplicación de numerosas técnicas de estrangulación.

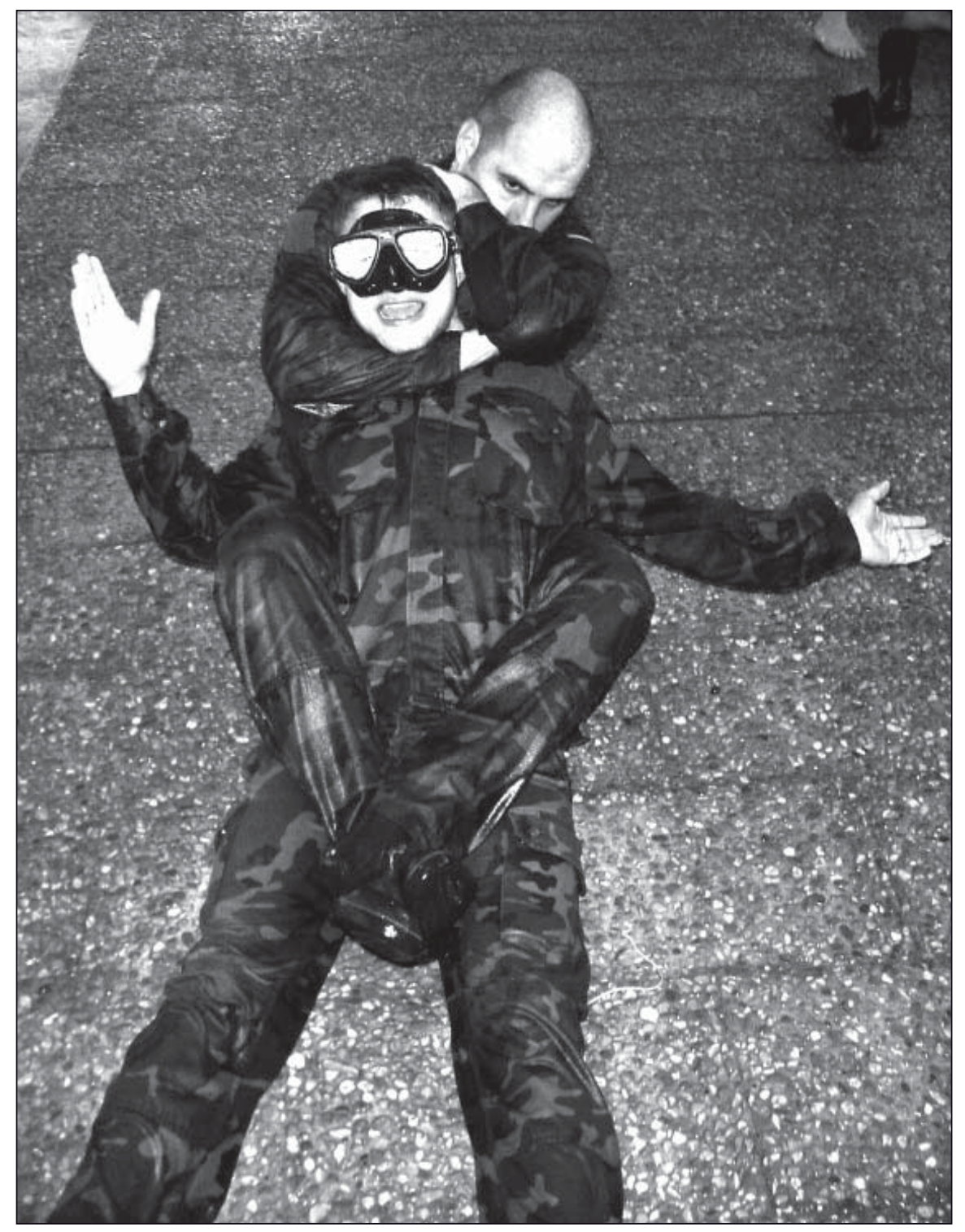

- Musculatura de los huesos púbicos, por encima de la articulación del fémur. El objetivo es anular sus piernas a la vez que se le impulsa en la dirección opuesta, que bien puede ser hacia arriba o hacia abajo.

\section{Luxaciones}

Las formas de luxación en el medio acuático van a tener una menor aplicación salvo que vayan dirigidas a articulaciones pequeñas (dedos o muñeca), ya que al ejecutarlas sin tener a favor la ley de la gravedad sólo se consigue un cambio de posiciones de ambos cuerpos, pero no una luxación o un bloqueo de las articulaciones. Todas aquellas luxaciones dirigidas a grandes articulaciones como el codo o el hombro solo consiguen cambiar de posición al adversario, por lo que deben ser tenidas en cuenta únicamente para esos efectos, salvo en el caso de que se limite el movimiento del contrario sujetándolo a la vez que se provoca la luxación.

En el conjunto de técnicas de luxación destacan aquellas luxaciones a la muñeca que exigen un movimiento de aducción o inclinación cubital, como 
pueden ser los Nikyo o Kote Kudaki (en su nomenclatura antigua). Las técnicas que exigen una extensión o una flexión de la mano carecen de eficacia, provocando principalmente los antecitados cambios de posición del enemigo salvo que se bloquee su cuerpo. También son de gran utilidad las hiperextensiones de los dedos combinándolas con giros en sus distintas direcciones. En este caso el objetivo dependerá del número de dedos sujetados, ya que a menor número de dedos aprehendidos mayor será la facilidad para romperlos, siendo mucho más complicado si se sujetan todos a la vez.

Otro subgrupo muy importante de luxaciones va a ser las luxaciones aplicadas a una zona vital como es el cuello. En esta zona cualquier luxación puede afectar al sistema nervioso o al sistema respiratorio, logrando con ello una incapacidad del adversario, pudiendo llegar a ser esta definitiva en el caso de fracturar sus cervicales.

\section{Estrangulaciones}

La respiración es una función vital de la que apenas se puede prescindir por unos breves minutos. Por tanto, el interrumpir este proceso mediante la aplicación de las estrangulaciones va a ser una de las formas más rápidas de anular al adversario. Se ha de pensar que, al fin y al cabo, como bien afirma Katsuhiko Kashiwazaki (1993: 21) "En sus orígenes ju jitsu, el shime waza fue diseñado para matar".

Las estrangulaciones son una de las armas más definitivas dentro del agua. Si la importancia de las estrangulaciones fuera del agua está fuera de toda duda, dentro de la misma sus efectos se multiplican exponencialmente. El trabajo de las estrangulaciones dentro del agua se fundamenta en los mismos principios que fuera:

- Cortar la llegada de oxigeno a los pulmones (estrangulaciones aéreas).

- Cortar el riego sanguíneo y por tanto la llegada de oxigeno al cerebro (estrangulaciones sanguíneas).

- Presiones nerviosas que a la vez cortan el suministro de oxigeno en cualquiera de las formas anteriores y luxan las cervicales.

- Expulsar el aire de los pulmones mediante presión directa, aplicada principalmente con las piernas.

Puesto que en el combate se suele portar el equipo militar, se podrán aplicar casi todas las estrangulaciones propias del Ju Jutsu, ya que el portaequipos de combate va a realizar las mismas funciones que las solapas del keikogui (traje de entrenamiento). Al igual que en los trabajos en tierra, las estrangulaciones que puedan ser realizadas por la espalda del enemigo serán habitualmente definitivas. En este caso, y puesto que no se cuenta con el suelo para mantener un control total del cuerpo de enemigo, el uso de las piernas como elemento de sujeción es fundamental. En el caso de realizarse de frente al enemigo, es de gran importancia el control de los brazos para evitar posibles contraataques. Asimismo, en este tipo de técnicas va a ser de gran utilidad que el soldado tenga el dominio necesario sobre el medio acuático, ya que la victoria le va a venir conferida por el hecho de realizar correctamente la técnica y poseer además una buena capacidad de apnea. 


\section{Proyecciones}

Como ya se ha señalado anteriormente, en el medio acuático las proyecciones no tienen utilidad al no existir un elemento contra el que golpear al enemigo, salvo que se este trabajando en profundidades menores de 20 o 30 centímetros, circunstancia que no se puede considerar como combate en el medio acuático propiamente dicho. En ese caso, la finalidad de la técnica consistiría en llevar al enemigo al agua para intentar reducirlo en ella, normalmente por ahogamiento. En cambio, en las formas de combate a mayor profundidad la finalidad de este tipo de movimientos será cambiar las posiciones respectivas de los adversarios, buscando el colocar al enemigo en una posición de desventaja para poder ejecutar otro tipo de técnica definitiva.

Figura 13:

Reducción del adversario por ahogamiento.

Fotografía cedida por la Revista Soldiers (J. Vicente Lumbreras)

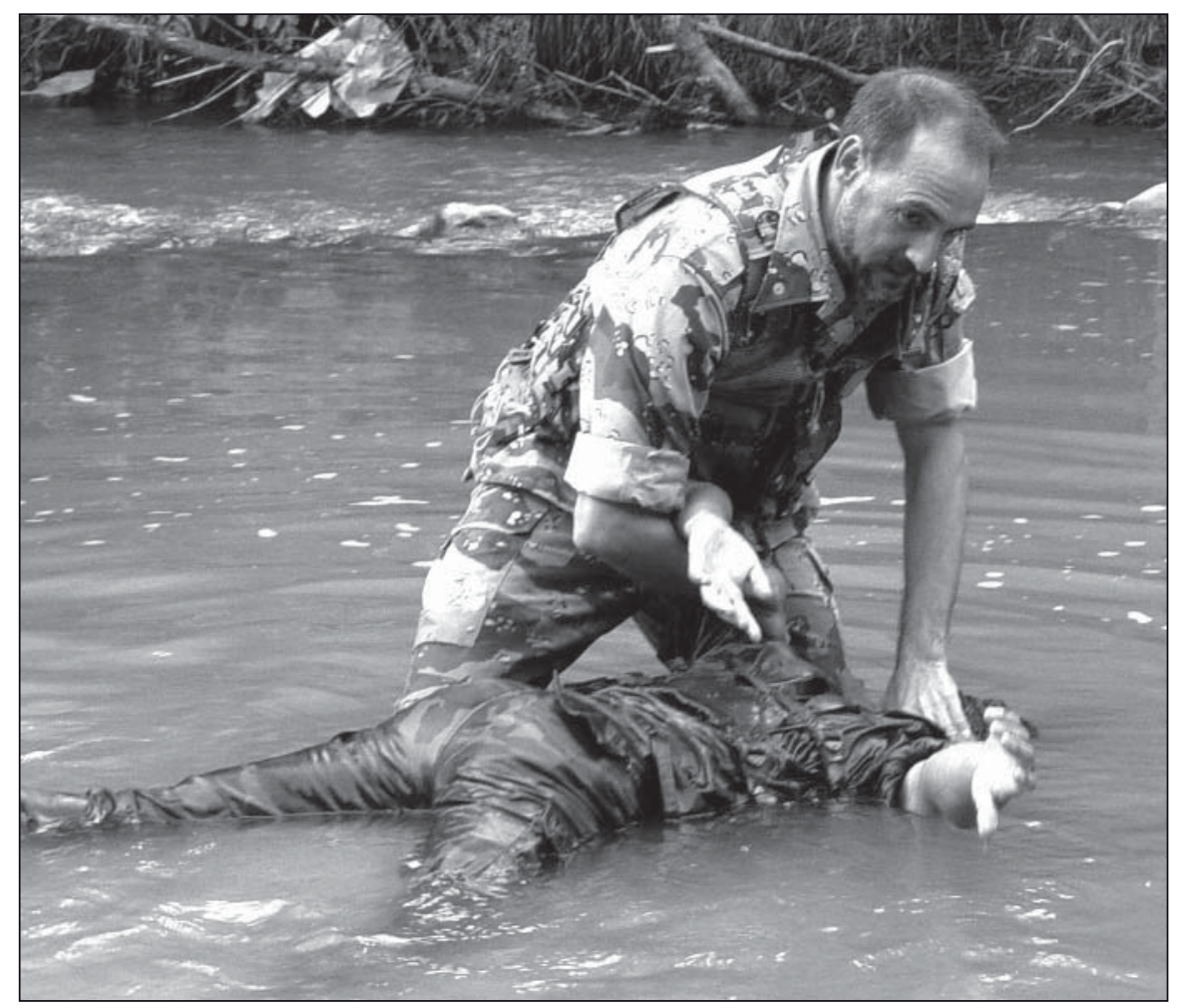

\section{Formas de lucha subacuatica}

En las formas de lucha subacuática existen otras peculiaridades respecto al combate en superficie. Una de estas peculiaridades es el equipo de buceo que porta el soldado. Por tanto, procederemos en primer lugar a realizar una somera descripción del equipo de buceo elemental, que puede clasificarse en dos modelos dependiendo del material que se porte. El primero es el equipo ligero (aletas, mascara y tubo), cuyos complementos serán el cinturón de lastre y los escarpines (zapatillas de goma para llevar dentro de las aletas). El segundo es el equipo pesado, compuesto por el chaleco hidrostático, el regulador con su grifería y los complementos (profundímetro, reloj, brújula, cuchillo, etc.). Con el equipo ligero se trabajará fundamentalmente en superficie, aunque se puedan llegar a alcanzar profundidades de entre 15 y 20 metros, dependiendo de las capacidades físicas del buceador. Con el segundo normalmente se trabajará hasta profundidades de hasta 50 metros. 
La máscara tiene como misión fundamental permitir al buceador ver bajo el agua, así como el tubo le permite respirar en superficie sin sacar la cabeza de ella. Las aletas van a ser elementos fundamentales ya que van a permitir el movimiento en el medio y además son un elemento estabilizador junto con el cinturón de lastre, prenda que, como su nombre indica, sirve para sujetar en la cintura las pastillas de plomo que van a permitir al buceador adquirir una flotabilidad neutra.

Dentro del equipo pesado el material fundamental es el chaleco hidrostático, que actúa como pulmón y tiene la misión de favorecer la flotabilidad, y las botellas con su grifería. Las botellas contienen aire comprimido que cuando se distribuye por la grifería y los manquitos permiten al buceador respirar bajo el agua y llenar o vaciar el chaleco hidrostático. Con el manómetro el buceador sabe en cada momento el aire que le queda en la botella, pudiendo calcular el tiempo que le queda de inmersión. El tiempo de inmersión va a depender del tipo de botella que se lleve, principalmente de su capacidad, y de la respiración del buceador. Como complementos el buceador debe llevar el profundímetro, que le permitirá saber a que profundidad se encuentra y a que profundidad máxima ha descendido. El reloj le va a permitir saber el tiempo que se ha permanecido bajo el agua, a efectos de poder preparar posteriormente otras inmersiones.

Dependiendo de la temperatura del agua se usará, además, el traje de neopreno o traje húmedo, siendo este obligado en aguas con una temperatura inferior a $15^{\circ}$ C. Estos trajes pueden ser de diversos tipos y grosores, siendo lo habitual entre 7 y $11 \mathrm{~mm}$., aunque la plancha de neopreno se fabrica en grosores de entre 2 y $11 \mathrm{~mm}$. Un mayor grosor proporciona una mayor protección contra el frío. Su acción de protección térmica se debe a que aunque permite la entrada de una pequeña cantidad de agua no se produce la renovación de esta, por su temperatura se equilibra con la temperatura corporal. La capucha es una parte muy importante del traje del buceador, ya que el cuerpo humano pierde gran cantidad de calor por la cabeza. Además, es un factor limitativo puesta que afecta a la movilidad de la cabeza y por tanto a la visión del buceador. Además de proteger de los cambios de temperatura, y en concreto del frío, otra misión no menos importante del traje es proteger al cuerpo de agresiones externas como son las rocas, animales, plantas urticantes, etc.

Existen otros tipos de equipos de buceo: equipos de circuito cerrado, trajes secos, etc. en los cuales no entraremos por ser sus adaptaciones mucho más técnicas en cuanto a material que en lo que afecta al combate acuático, objeto del presente trabajo.

Dentro del combate cuerpo a cuerpo en el medio subacuático, el conocimiento del equipo del buceador es fundamental, ya que su desconocimiento, haciendo un símil, sería como intentar combatir en tierra sin saber andar. Además dicho equipo, que a la vez sirve de soporte al buceador, puede ser

Figuras 14, 15 y 16:

La extracción de la máscara del oponente es una de las principales acciones tácticas en la lucha subacuática.

El combate subacuático genera situaciones posicionales insólitas, imposibles en el combate en el medio terrestre. 
usado contra el enemigo. También es importante el uso del equipo de buceo del enemigo contra si mismo, ya que, por ejemplo, mediante la manipulación de su máscara éste puede quedar cegado. Se pueden aplicar, asimismo, estrangulaciones con sus manguitos, o usar su chaleco hidrostático, aportando o restando flotabilidad y con ello alterando su equilibrio en el medio acuático. Ha de tenerse en cuenta que la posición del cuerpo es un factor determinante en el agua. Dicha posición se logra, mediante tres elementos fundamentales: las aletas, el cinturón de lastre y el chaleco hidrostático. A estos tres elementos les complementa la adecuada colocación del equipo, que puede desequilibrar el peso hacia uno u otro lado. Este hecho puede afectar de forma determinante en un combate con otro buceador.

\section{El uso del cuchillo o machete}

Si existe un arma que es inherente a los buceadores, esta el cuchillo. De hecho la legislación de algunos países obliga a los buceadores a portar dicha arma-herramienta, que en el agua puede servir tanto para cortar redes que atrapen al buceador como para cualquier otra operación auxiliar que necesite.

Si en tierra una buena técnica de cuchillo puede ser decantadora en una lucha, en el medio acuático es esencial, ya que va a conseguir lo que no se puede con un golpe o una presión, y sobre todo va a aumentar la eficacia de los mismos. En distancias cercanas seguirá las mismas premisas que los golpes, buscando puntos vulnerables del cuerpo y cortes a partes del equipo del otro buceador. En distancias medias y lejanas sencillamente no es utilizable, ya que su eficacia es nula ${ }^{1}$. No debe olvidarse que el cuchillo no solo es un arma cortante, sino que también puede usarse su pomo como arma para golpear o presionar, siguiendo los mismos principios que las armas naturales del cuerpo.

Figura 17:

Corte de cuchillo en

la nuca.

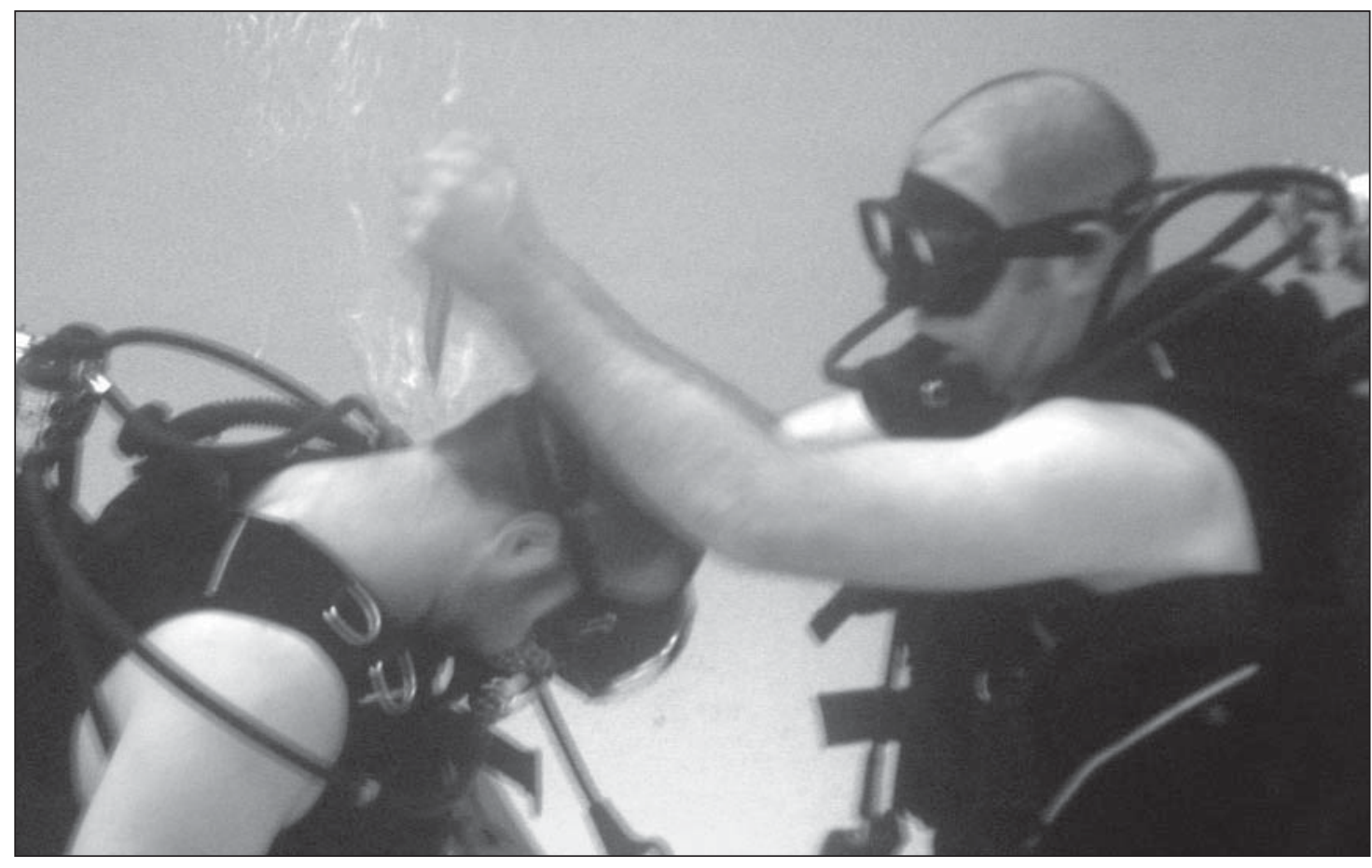



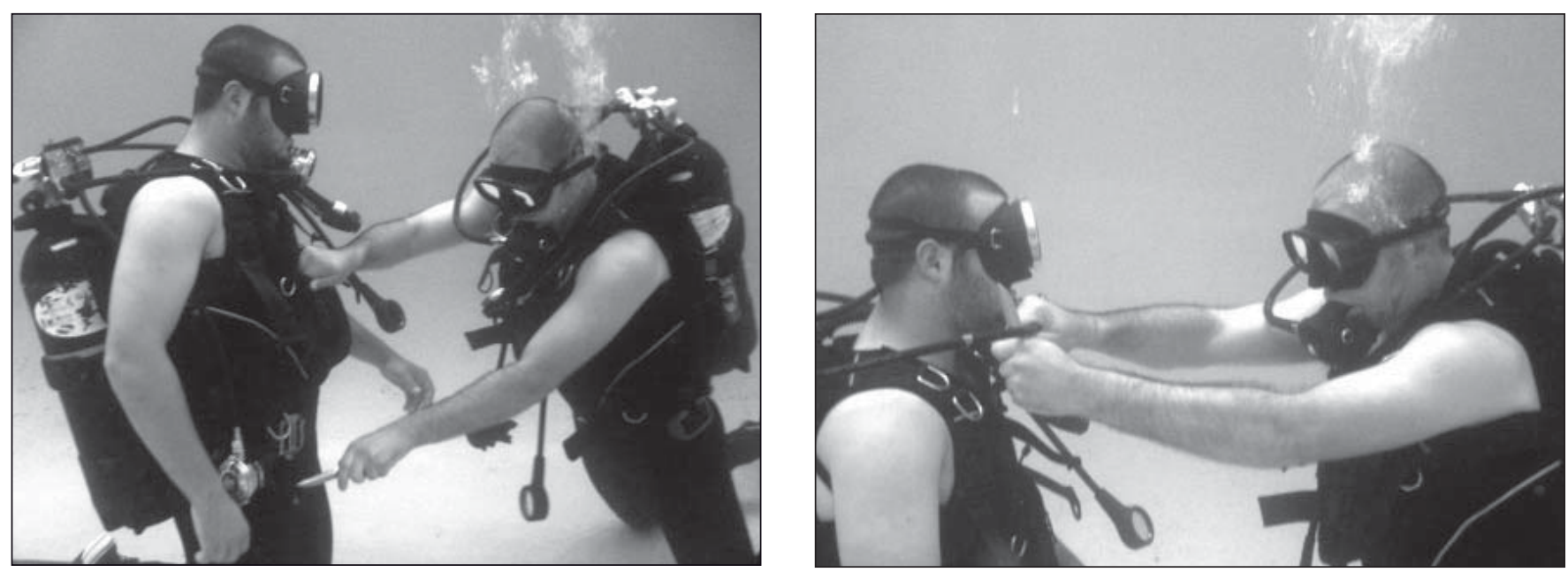

Los puntos más vulnerables del equipo a atacar con el cuchillo son los manquitos del regulador (cortarán el flujo de aire al cuerpo) o del manómetro (el aire escapara directamente) y el jacket, que al igual que el elemento anterior dejará escapar el aire e impedirá al buceador mantener la flotabilidad neutra y dificultándole igualmente el ascenso. Si el buceador lleva traje seco en vez de traje húmedo (trajes de neopreno) su flotabilidad y su circuito de aire también se verán afectados al cortarle el traje, ya que dependiendo de la amplitud del corte la perdida de aire será mayor y su traje se inundará. En el cuerpo se atacarán fundamentalmente las partes desprotegidas, como son los laterales y la parte frontal del cuello y las ingles, teniendo en cuenta que el grosor del traje afectará a la profundidad del corte realizado según sea la fuerza con la que se ejecute.

\section{Golpes y presiones}

Los golpes debe aplicarse sobre puntos muy vulnerables, es decir cara (ojos, nariz, boca) y cuello (frontal y lateral). Estos puntos coinciden con la ubicación de determinadas partes del equipo de buceo como son la mascara de buceo y el regulador de aire.

Bajo el agua, todo buceador o combatiente que cae en ese medio y es atacado y necesita defenderse, o pretende atacar a un buceador, debe buscar en primer lugar cegar al enemigo, siendo el medio más rápido extraerle la mascara o en su defecto abrirle una vía de agua que le impida ver correctamente, al menos durante unas décimas de segundo. El segundo golpe debe ir dirigido al regulador para impedir la correcta respiración del enemigo, siendo un factor determinante sustraérselo, pudiendo incluso apoderarnos de él como fuente de aire.

Las presiones a determinados puntos vulnerables van a tener como limitación el traje de neopreno, ya que este va a hacer casi imposible que estas sean efectivas puesto que amortigua la presión que pueda ejercerse. En este caso, para conseguir el mismo efecto debe usarse el pomo del cuchillo, el kubotán ${ }^{2}$ o cualquier objeto similar que permita darle mayor contundencia a dichas presiones. De no realizarlas con un objeto contundente o un arma de las citadas anteriormente, serán únicamente aplicables aquellas dirigidas a la nariz, la boca y la traquea, teniendo en cuenta que todos los puntos anteriores pueden estar limitados por el equipo de buceo (latiguillos del equipo de respiración, mascara, regulador, etc.). 


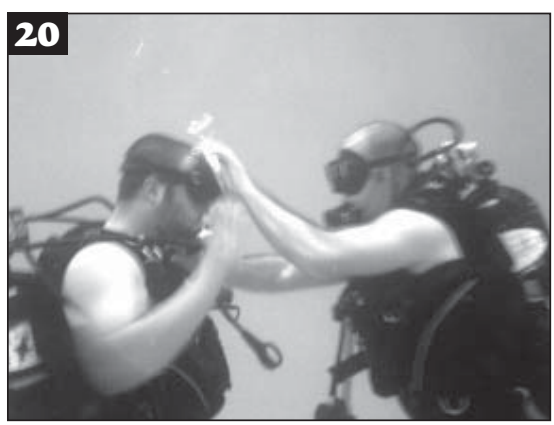

Figura 20:

Golpe a la máscara.
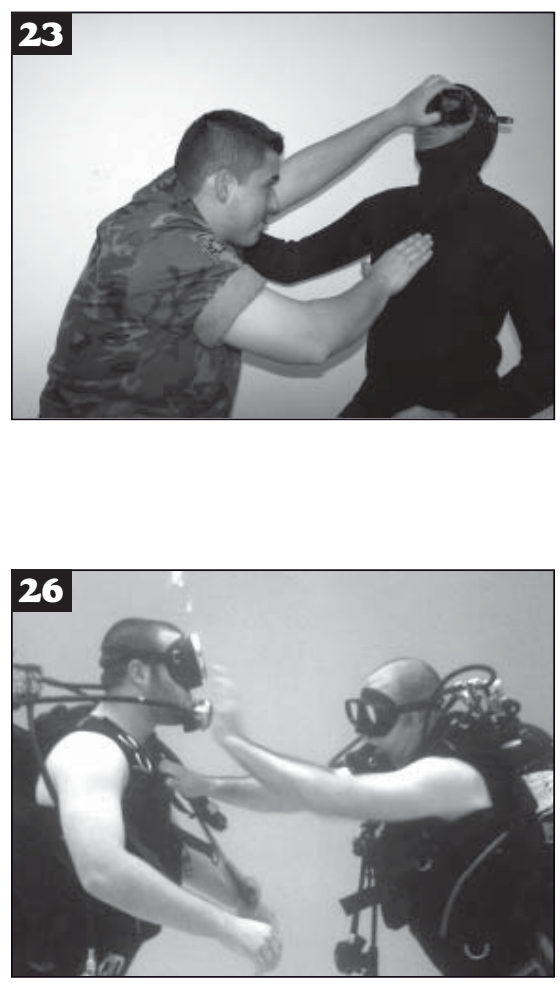

Figura 26:

Golpe al regulador.
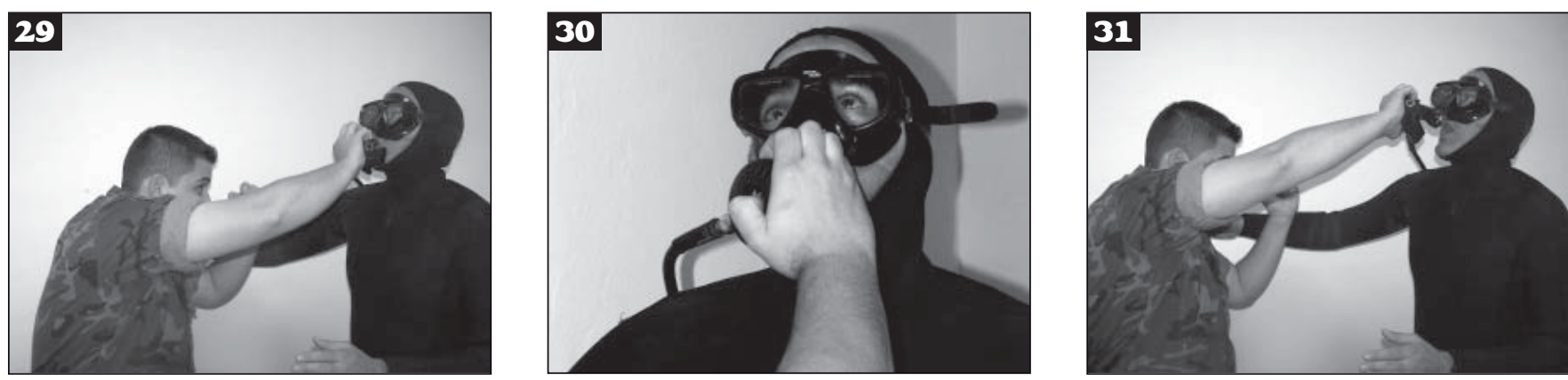

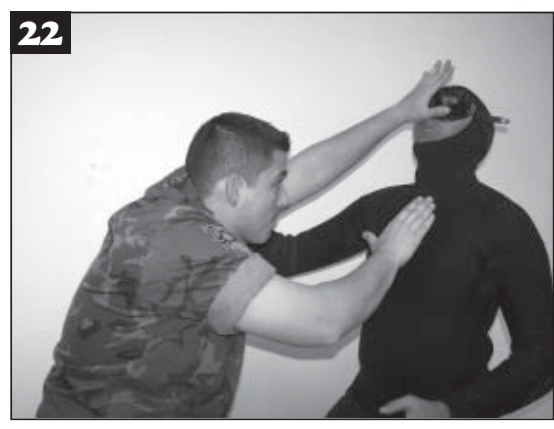

Figuras 21 a 25:

Secuencia de golpeo y extracción de la máscara (dos finales).
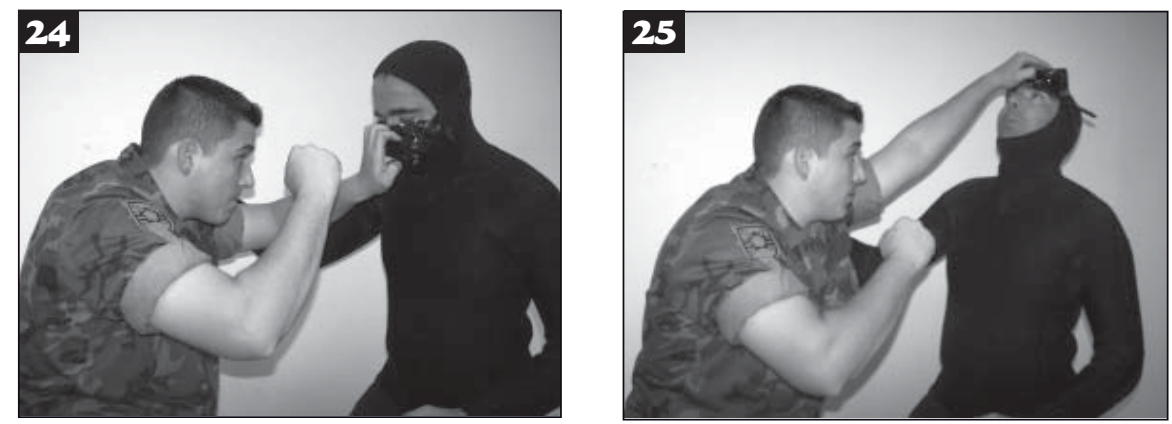

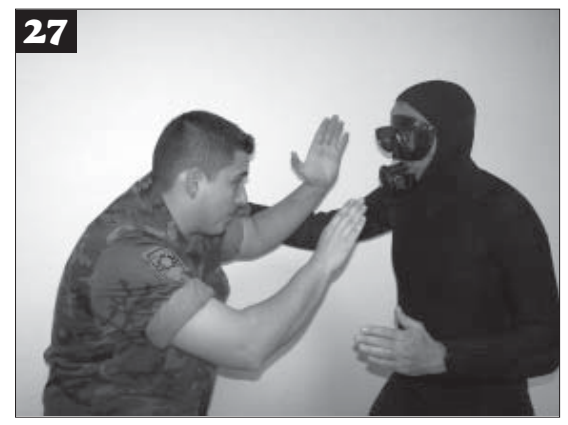

Secuencia de golpeo y extracción del regulador. El atacante aprieta el purgador del regulador para mandar mayor caudal de aire al adversario (detalle). 


\section{Controles}

Los controles, como bloque técnico, van a ser muy limitados dentro este tipo de lucha. El principal motivo es la falta de acción de la gravedad y la ausencia en muchos casos de un elemento de apoyo (el suelo) hacia donde ejercer la presión. Serán útiles algunos controles que permitan transportar al adversario dentro del agua. Para este tipo de acciones son aconsejables todas aquellas técnicas que se produzcan sobre una articulación pequeña (muñeca) o sobre una grande que permita al combatiente además de luxar, mantener el agarre del individuo impidiendo que desaparezca el control por falta del elemento de apoyo. Como ejemplo citar dos técnicas de conducción como son el Ude Nobashi (Kote Gatame en su forma moderna) e Hiji Dori.

\section{Luxaciones}

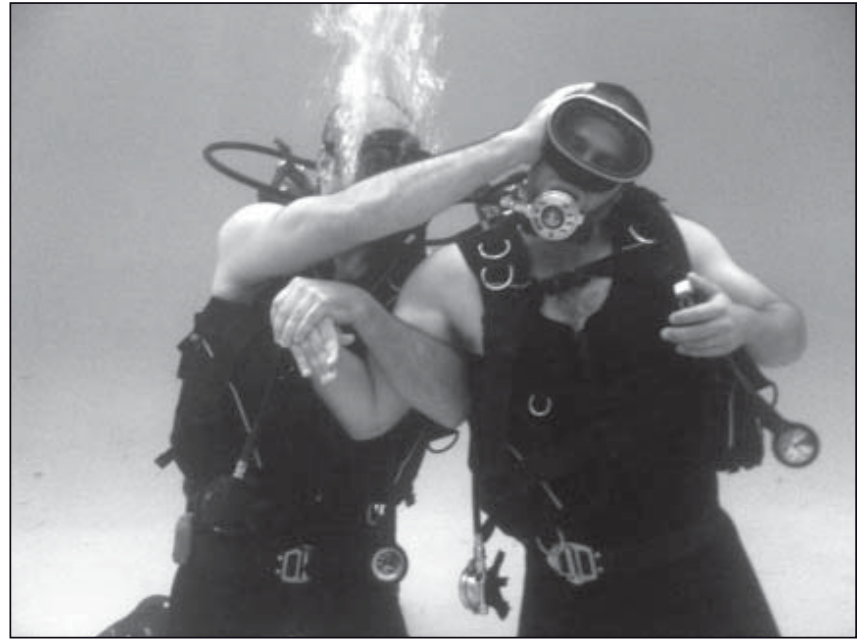

Figura 32:

Control sobre la muñeca (ude-nobashi) y presión sobre el oído (punto mimi).

Las formas de luxación en el combate en profundidad van a tener muy poca aplicación, salvo, como ya se citó en el combate en superficie, aquellas que vayan dirigidas a articulaciones pequeñas (dedos o muñeca) y las dirigidas a articulaciones grandes que permitan tener el cuerpo de enemigo inmovilizado mientras se ejerce la palanca.

Pueden trabajarse algunas formas básicas de luxación para transportar bajo el agua a un enemigo buceador en caso de ser necesario. Puesto que se basan en los mismos principios que las hacen útiles en tierra, y al realizarse sobre articulaciones pequeñas y en una posición paralela a la del enemigo, permiten realizar el aleteo con total normalidad, pudiendo controlar igualmente sus elementos de respiración. Dicha técnica es conveniente que se realice llevando al enemigo cegado (sin máscara o, como mínimo, llena de agua).

\section{Figura 33:}

Luxación de muñeca (kote-kudaki).

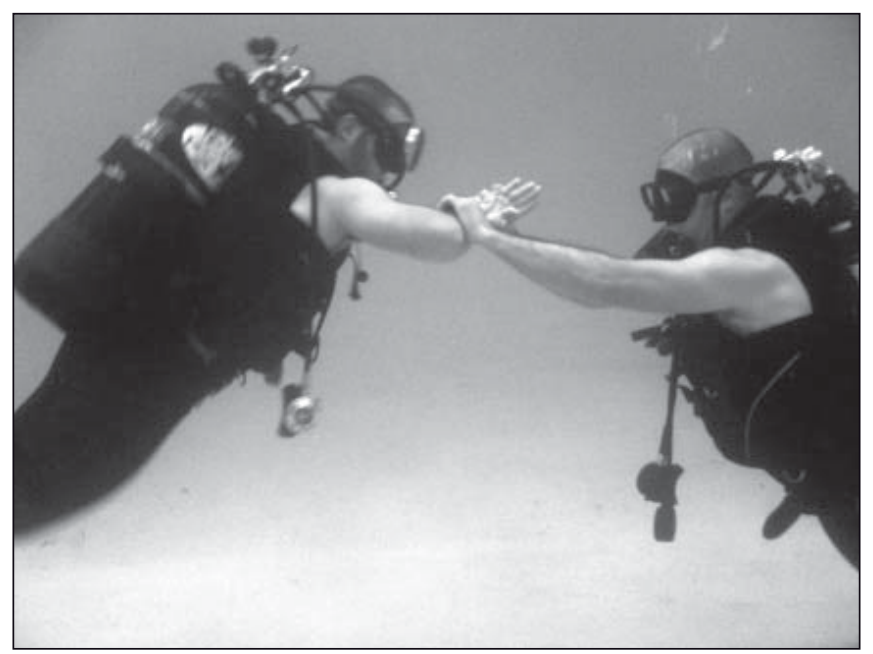

\section{Figura 34:}

Forma de conducción mediante un control a la muñeca.

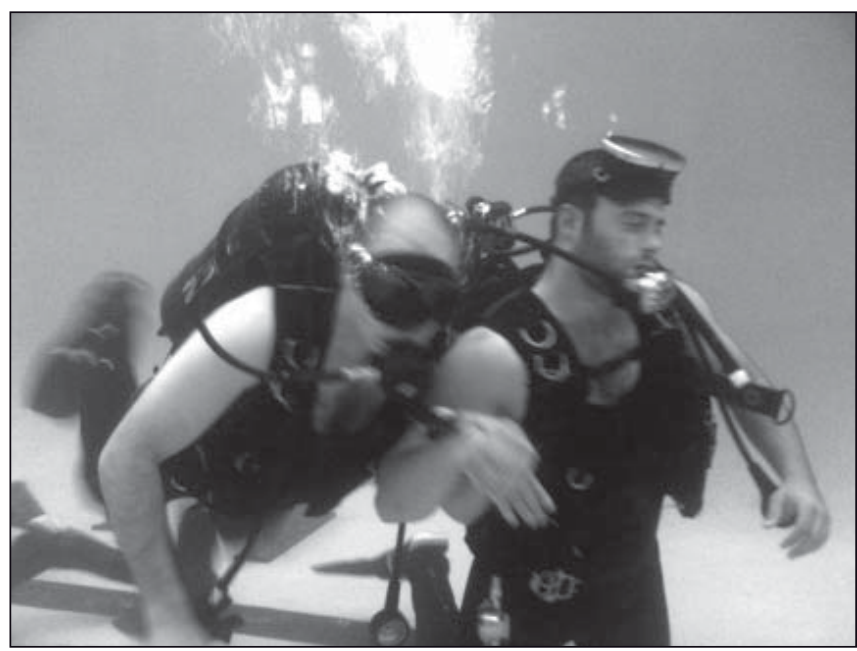




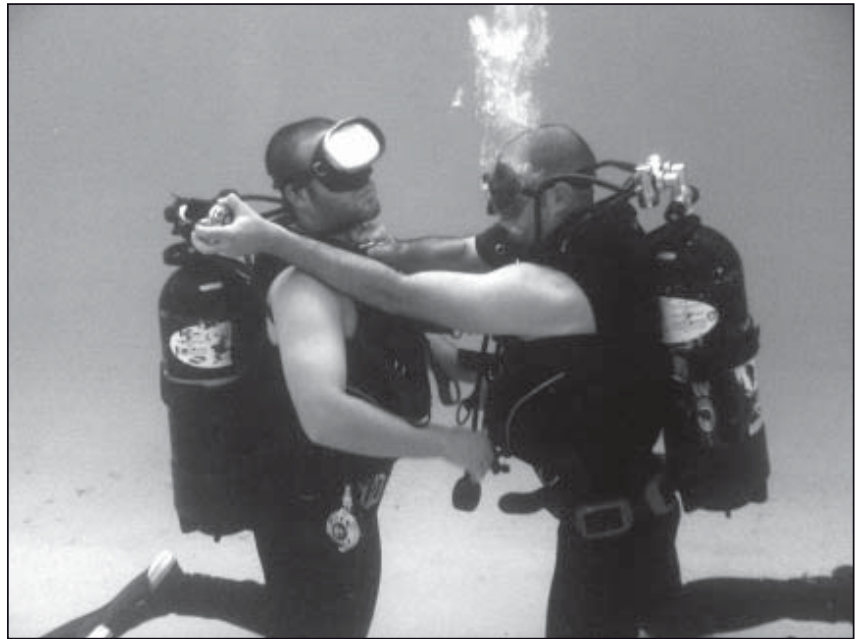

Figura 35: Extracción del regulador de aire del oponente y posterior estrangulación con el mismo.

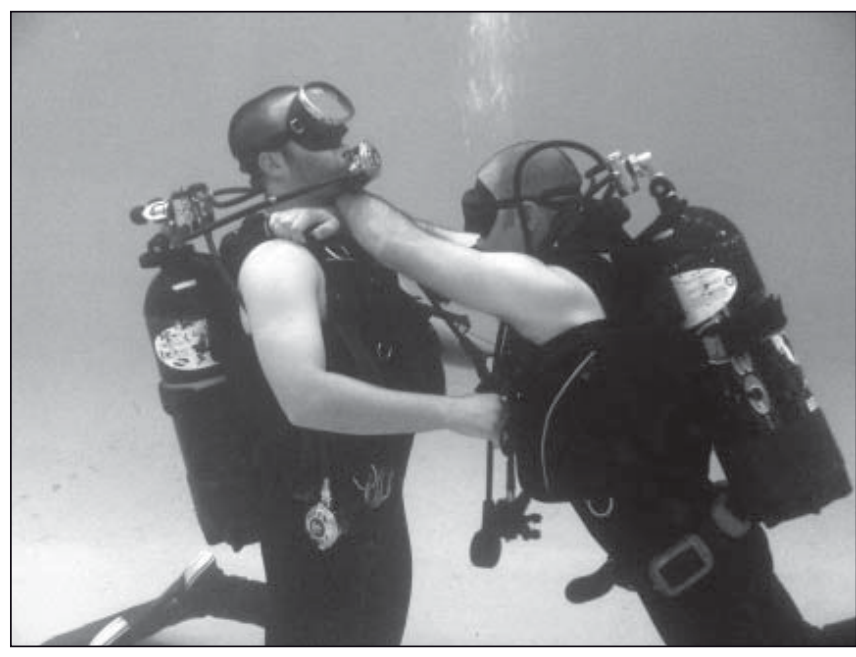

Figura 36: Forma de estrangulación (juji-jime).

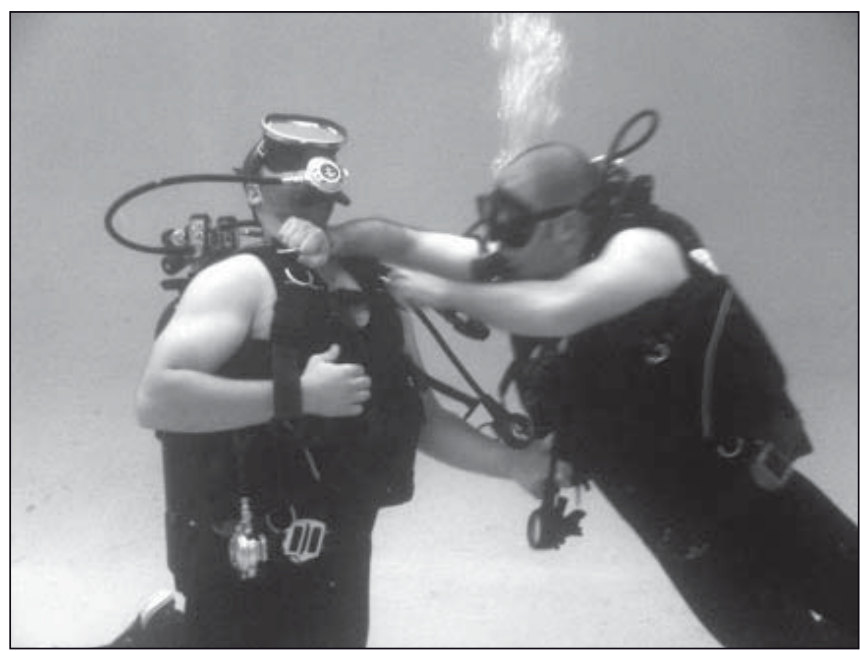

Figura37: Forma de estrangulación (kata-juji-jime).

\section{Estrangulaciones}

Dentro del agua se aplicará una cuarta forma, que se suma a las anteriormente citadas en el combate en superficie, provocada por aumento del caudal de aire mediante el regulador del equipo de respiración. Con ello se consigue insuflar aire y agua en exceso, impidiendo la respiración al enemigo. Este tipo de técnicas van a ser de gran utilidad cuando el enemigo es buceador y será definitiva cuando no lo es. Unidas a un total control de nuestra posición y de la del enemigo van a suponer un $90 \%$ de la eficacia del combate en profundidad, e incluso en superficie. Asimismo, debe tenerse en cuenta el uso del equipo de buceo del enemigo en contra de él mismo. En este caso, el primer paso va a consistir siempre en quitar el regulador de la boca del adversario.

En la aplicación técnica de las estrangulaciones hay que tener en cuenta la dificultad para situarse con respecto al adversario, ya que el equipo de buceo, al igual que ayuda a respirar bajo el agua, también impide muchos movimientos. Por ejemplo, en las estrangulaciones por la espalda se debe de tener en cuenta que la presencia de las botellas impide acercarse tanto como en superficie. Igualmente la presencia de los manguitos puede dificultar la sujeción del cuello con las manos. El chaleco hidrostático impide la sujeción de las piernas a la altura del tórax, y por tanto que se pueda obligar al adversario a expulsar el aire de sus pulmones mediante la presión de estas.

\section{Armas Auxiliares}

Existen otros tipos de armas auxiliares y/o circunstancias que pueden ser usadas en el combate acuático, como pueden ser los cabos (cuerdas) o los remos de las embarcaciones. Este tipo de armas puede ser utilizado tanto de forma defensiva como ofensiva, ya que una de las facetas más importantes del combate en el medio acuático es la defensa y abordaje de embarcaciones. Igualmente, existen otras armas adecuadas como por ejemplo el kubotán o el yubi bo, muy apropiado para aumentar los efectos de los golpes o las presiones.

\section{Reflexiones finales}

Las artes marciales se manifiestan en numerosos ámbitos de la vida, como son la autodefensa, el deporte, las prácticas para el mantenimiento de la salud, la educación o el ámbito del combate militar. Si bien las artes marciales fueron creadas originalmente para ser utilizadas en el medio terrestre, muchos de sus principios y técnicas pueden ser de gran utilidad en un medio "poco habitual" como es el medio acuático.

Las formas de combate acuático son aplicables en diversos contextos como son el combate militar o las operaciones policiales. También tienen una gran impor- 
tancia en las zafaduras utilizadas por los socorristas en situaciones de salvamento acuático.

Con todo, y aunque a lo largo del presente trabajo hayamos tratado de dejar la utilidad real del combate acuático, no es menos cierto que para el público civil esta parte de las artes marciales quedará como algo raramente trabajado (por la dificultad de obtener los medios necesarios y el propio sentido de dicha práctica) o como un trabajo exclusivamente tradicional (como en ciertas escuelas ya citadas).

\section{Bibliografía}

Iguaran, J. (1972). Historia de la natación antigua y de la moderna de los Juegos Olimpicos. Valverde: Tolosa.

Ivars, J. y Rodríguez, T. (1987). Historia del Buceo, su desarrollo en España. Murcia: Mediterráneo.

Jardí, C. (1996). Movernos en el agua. Barcelona: Paidotribo.

Kashiwazaki, K. (1993). Shime Waza. Barcelona: Paidotribo.

Lewin, G. (1979). Natación. Madrid: Augusto Pila Teleña.

Lumbreras, J.V. (1999). "Combate en aguas poco profundas". Soldiers, 49, 46 49.

Mando de Adiestramiento y Doctrina del Ejército de Tierra (MADOC) (2005). Plan de Instrucción y Adiestramiento para el Regimiento de Pontoneros y Especialidades de Ingenieros $N^{\circ} 12$.

MADOC. (2005) Plan de Instrucción y Adiestramiento para la Unidad Escuela de Buceo del Ejército de Tierra.

MADOC; (1999) OR5-404, Zapador Anfibio, procedimiento de empleo, 1999, $1-10$.

Planellas, P.-R. (1995). Jintay Kyusho. Los puntos vulnerables del cuerpo humano. Barcelona: Alas.

Planellas, P.-R. (2002). Enciclopedia de las armas japonesas: historia, leyendas, mitología, técnica, morfología, filosofía, ética, artes marciales, Vol 2. Barcelona: Alas.

Ratti, O. y Westbrook, A. (1994): Los Secretos del samurai. Las artes marciales en el Japón feudal. Madrid: Alianza Deporte.

Reyes, R. (1998) Evolución de la natación española a traves de los campeonatos de natación de invierno y verano desde 1977 a 1996 (Tesis doctoral). Las Palmas de Gran Canaria: Universidad de Las Palmas de Gran Canaria.

Saavedra, J.M., Escalante, Y. y Rodríguez, F.A. (2003). "La evolución de la natación". Educación Física y Deportes (revista digital), 66. Accesible en http://www.efdeportes.com/efd66/natacion.htm. [Consulta 20/07/2006].

\section{Agradecimientos:}

A todo el personal de la Unidad Escuela de Buceo del E.T. por su apoyo para la realización de las fotografías, la aportación de todo el material, tanto técnico como práctico, necesario para este artículo, pero sobre todo por ser el banco experimental de muchas de las actividades aquí descritas.

A Pablo Herranz Julvez, Moisés López Prados, Miguel A. Marin Sancho y Paulino Rodríguez Castro, que han sufrido directamente todas las técnicas y han hecho posible las fotografías.

\section{Notas al pie}

${ }^{1}$ Las distancias del combate van a ser las que marquen la forma en las que este se va a realizar. Se entiende por distancia lejana aquella en la que no se llega a tocar el cuerpo del adversario ni con las piernas ni con un arma en las manos. Por distancia media se entenderá cuando tanto con las piernas como con un arma en las manos (normalmente un cuchillo) se tenga contacto con el adversario. La distancia cercana es aquella en la que tanto las manos de uno como del otro pueden tener contacto con el cuerpo del adversario. Por último, en la distancia cuerpo a cuerpo los cuerpo de ambos adversarios están trabado en un agarre o simplemente están cuerpo con cuerpo. En el uso del cuchillo en el agua solo sirve el cuerpo a cuerpo ya que en las anteriores pierde potencia y puntería, y por lo tanto toda su eficacia.

${ }^{2}$ Este tipo de arma entra dentro del kakushijutsu (técnicas con armas ocultas). Morfológicamente hablando suelen ser cilindros de $20 \mathrm{~cm}$. aproximadamente y de material variable (madera, hierro, etc.), pueden presentar una cuerda en el medio que permita fijarlos a la mano (yubi bo). Esta arma es propia del Ju Jutsu tradicional. Dicha disciplina contaba con armas auxiliares que potenciaban sus efectos como en este caso. El kubotán tenía como misión aumentar el efecto de los golpes y las presiones efectuadas de por sí con las armas naturales del cuerpo. Además en niveles más avanzados es usado como elemento auxiliar para la realización de luxaciones, proyecciones y estrangulaciones. También se usa militarmente una variante de este que lleva unida una cuerda o cadena (conocido tradicionalmente en el budo japonés como Te no Uchi). 